OPEN ACCESS

Edited by:

Marcello Leopoldo,

University of Bari Aldo Moro, Italy

Reviewed by:

Alejandra Tomas,

Imperial College London,

United Kingdom

Holger Stark,

Heinrich Heine University of

Düsseldorf, Germany

*Correspondence:

Lupei Du

dulupei@sdu.edu.cn

Specialty section:

This article was submitted to

Medicinal and Pharmaceutical

Chemistry,

a section of the journal

Frontiers in Chemistry

Received: 16 November 2021

Accepted: 11 January 2022

Published: 31 January 2022

Citation:

Ma S, Li Z, Yang Y, Zhang L, Li M and Du $L$ (2022) Fluorescent Ligand-Based

Discovery of Small-Molecule

Sulfonamide Agonists for GPR120.

Front. Chem. 10:816014.

doi: 10.3389/fchem.2022.816014

\section{Fluorescent Ligand-Based Discovery of Small-Molecule Sulfonamide Agonists for GPR120}

\author{
Siyue Ma, Zhenzhen Li, Yueli Yang, Ling Zhang, Minyong Li and Lupei Du*
}

Key Laboratory of Chemical Biology (MOE), Department of Medicinal Chemistry, School of Pharmacy, Cheeloo College of Medicine, Shandong University, Jinan, China

As a critical member of G protein-coupled receptors (GPCRs), G protein-coupled receptor 120 (GPR120) is a potential target for many physiological diseases, such as type 2 diabetes mellitus, inflammation, and obesity. Considering that small-molecule fluorescent ligands can combine the advantages of visualization, high sensitivity and selectivity, we initially undertook an effort to develop a series of fluorescent ligands to track GPR120 and establish a method to screen GPR120 agonists. The representative fluorescent ligand N1 possesses suitable optical property, equitable biological activity, and high fluorescence imaging feasibility, therefore, based on compound N1, we subsequently founded a bioluminescence resonance energy transfer (BRET) competition binding assay to screen three series of sulfonamide GPR120 agonists we developed herein. The activity evaluation results revealed that compound D5 was a potent GPR120 agonist with high activity and selectivity. Moreover, compound D5 exhibited a significant glucose-lowering effect in $\mathrm{db} / \mathrm{db}$ mice, which indicates its potential application in the treatment of type 2 diabetes mellitus in vivo. It is anticipated that our fluorescent ligand-based method is a useful toolbox and will find broad applications in the discovery of small-molecule agonists for GPR120.

Keywords: GPR120 agonist, fluorescent ligand, BRET, glucose-lowering effect, type 2 diabetes

\section{INTRODUCTION}

G protein-coupled receptors (GPCRs) are the most significant type of membrane protein family involved in signal transduction on the cell surface. (Civelli et al., 2013) They can stimulate signals outside the cell membrane into the cell through receptors on the cell membrane concerning the mechanisms of many diseases. (Ichimura et al., 2012; Hauser et al., 2017; Gurevich and Gurevich, 2019) G protein-coupled receptor 120 (GPR120) is one member of the GPCRs family, known as the $\omega 3$ fat receptor 1. Like other GPCRs, it contains an extracellular N-terminal domain, an intracellular C-terminal domain, (Shimpukade et al., 2012) and seven transmembrane structures. (Leung and Zhang, 2014) GPR120 is highly expressed in the small intestine of humans and mice, and abundantly in adipocytes and macrophages. (Hirasawa et al., 2005) Its expression level on tissues and cells reveals that GPR120 may be related to the presence of many diseases, such as diabetes, inflammation, and

\footnotetext{
Abbreviations: BRET, bioluminescence resonance energy transfer; $\mathrm{Ca}^{2+}$, calcium ion; FFA4, free fatty acid receptor 4; GPCRs, G protein-coupled receptors; GPR40, G protein-coupled receptor 40; GPR120, G protein-coupled receptor 120; Rluc, Renilla luciferase.
} 
obesity. (Leung and Zhang, 2014; Hilgendorf et al., 2019; Miyamoto et al., 2019) Therefore, GPR120 can induce the secretion of GLP-1 under the induction of $\omega-3$ fatty acids, which can inhibit eating and promote insulin synthesis. (Alvarez-Curto et al., 2016) Also, when a ligand activates GPR120, $\beta$-arrestin2 can be recruited to the cell membrane and coupled with GPR120, and then enter the cytoplasm through endocytosis, thereby inhibiting the binding of TAB1 and TAK1, and achieving the purpose of interfering with proinflammatory signaling. (Yan et al., 2013) Therefore, GPR120 has become an essential target for diabetes, inflammation, and obesity.

Scientists have discovered and researched many natural and synthetic agonists targeting GPR120. (Milligan et al., 2017) GW9508 is the first GPR120 small molecule agonist determined in recent years. (Garrido et al., 2006) In 2010, Suzuki et al. found that NCG21 could promote the secretion of GLP-1 in STC-1. (Sun et al., 2010) In 2012, a small molecule TUG-891 targeting GPR40 was found to have high selectivity to GPR120 as well. (Azevedo et al., 2016) All these three are aromatic fatty carboxyl compounds. In 2014, Steven et al. reported the first small sulfonamide compound, GSK137647A, with high agonistic activity with GPR120. (Sparks et al., 2014) In vitro studies exhibited that the molecule discloses the best selectivity so far (Scheme 1). (Hansen and Ulven, 2016)

With the deepening of the research on GPR120, it is necessary to develop a GPR120 fluorescent ligand to monitor the receptorligand interaction in a real-time manner (Ma et al., 2014) to establish a method to screen more potent GPR120 agonists. (Iliopoulos-Tsoutsouvas et al., 2018) Small-molecule fluorescent tracers are divided into three parts: recognition groups, linker chains, and fluorophores. (Ma et al., 2016) We have successfully designed and synthesized a series of aromatic acid-based fluorescent ligands on the scaffold of TUG-1197 previously. (Liu et al., 2019) Because GSK137647A has high selectivity, we chose it as a recognition group to develop another series of small-molecule fluorescent ligands herein.
Because the ligand-binding region of GPR120 belongs to a high-viscosity and low-polarity environment, we chose the environmentally sensitive fluorophores naphthalenediimide (Klymchenko, 2017; Liu et al., 2017) to make the probe emit weak fluorescence in an aqueous solution, while in the lowpolarity environment emits strong fluorescence.

Bioluminescence resonance energy transfer (BRET) is a mature method for detecting the interactions between proteinprotein and has been applied to GPCRs signal transduction and drug screening. (Stoddart et al., 2015) When a bioluminescence donor and a fluorescent acceptor are close enough to interact, energy transfer will occur. In the BRET experiments, we chose Renillaluciferase (Rluc) as a bioluminescence donor and naphthalimide as an acceptor because the excitation spectrum of naphthalimide fluorophore and the emission spectrum of the Rluc receptor tag is close to the ideal overlap. We established a BRET competition binding assay with the most potent probe to screen other ligands on GPR120. Agonists with good preliminary BRET screening results are used for subsequent calcium ion $\left(\mathrm{Ca}^{2+}\right)$ assay, bias test, (Rajagopal et al., 2011) and blood glucose experiment in mice. (McCoull et al., 2017)

\section{RESULTS AND DISCUSSION}

\subsection{The Design of Fluorescent Ligands (N1-N3)}

GPR120 ligands with fluorescent properties can monitor the interaction between ligand and GPR120 in real-time. Because the ligand-binding area is of high viscosity and low polarity, we need to develop environment-sensitive fluorescent ligands. GSK137647A has good pharmacological activity and selectivity to GPR120 than G protein-coupled receptor 40 (GPR40), so we selected it as the pharmacophore. For the fluorophore, we selected the naphthalimide, which is environment-sensitive. Considering that the length of linkers will also affect fluorescent ligands activity, we designed different lengths of linkers (Scheme 2).<smiles>O=C(O)CCc1ccc(NCc2cccc(Oc3ccccc3)c2)cc1</smiles>

GW9508 ${ }^{13}$

$\mathrm{EC}_{50}(\mathrm{FFA} 4): 851 \mathrm{nM}$

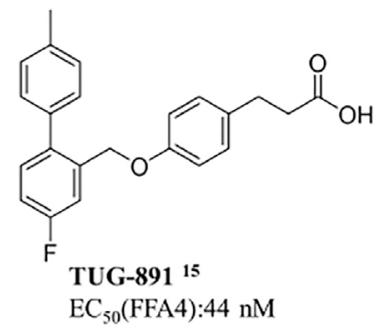<smiles>O=C(O)CCCc1ccc(OCCN(c2ccccc2)c2ccccn2)cc1</smiles><smiles>COc1ccc(S(=O)(=O)Nc2c(C)cc(C)cc2C)cc1</smiles>

GSK137647A ${ }^{16}$

$\mathrm{EC}_{50}(\mathrm{FFA} 4): 501 \mathrm{nM}$

SCHEME 1 | Current agonists of GPR120. 


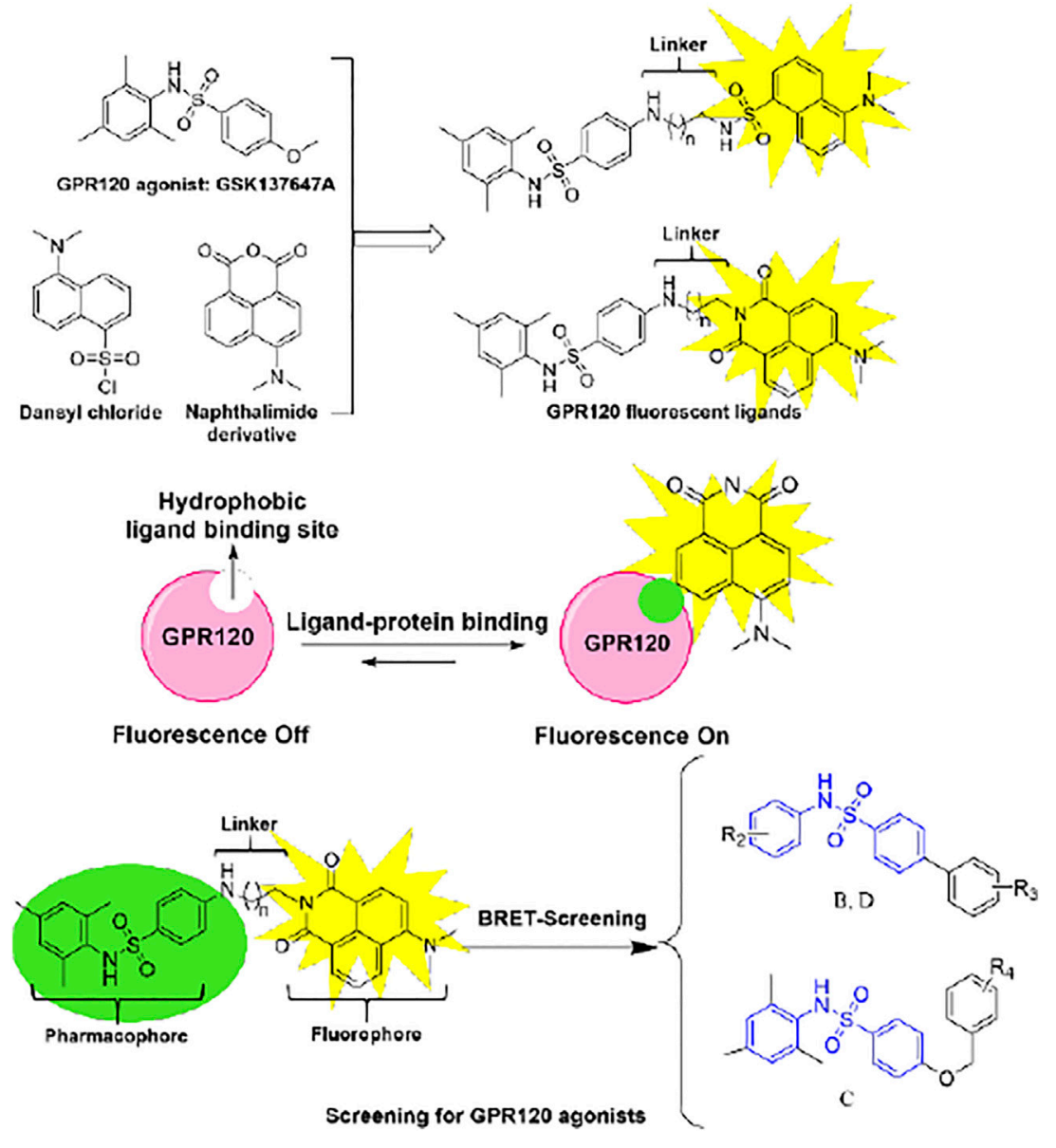

SCHEME 2 | Design flow and mechanism of GPR120 fluorescent ligands.

\subsection{Synthesis of Fluorescent Ligands (N1-N3)}

The synthetic route of fluorescent ligands N1-N3 is depicted in Scheme 3, in which intermediate 1 is afforded by sulfonamide reaction between 2,4,6-trimethylaniline and $p$-iodobenzenesulfonyl chloride. After a two-step substitution reaction, we obtained the fluorescent ligands N1-N3.

\subsection{The Spectroscopic and Pharmacologic Properties of Fluorescent Ligands}

The excitation wavelength, emission wavelength, fluorescence quantum, and ultraviolet maximum absorption wavelength of fluorescent ligands are depicted in Table $\mathbf{1}$ and Supplementary Figure S7. The stokes shift values are all higher than $60 \mathrm{~nm}$ (Supplementary Figures S1-S3) in PBS buffer $(\mathrm{pH}=7.4)$. The

TABLE 1 | Spectroscopic properties and pharmacological properties of our fluorescent probes.

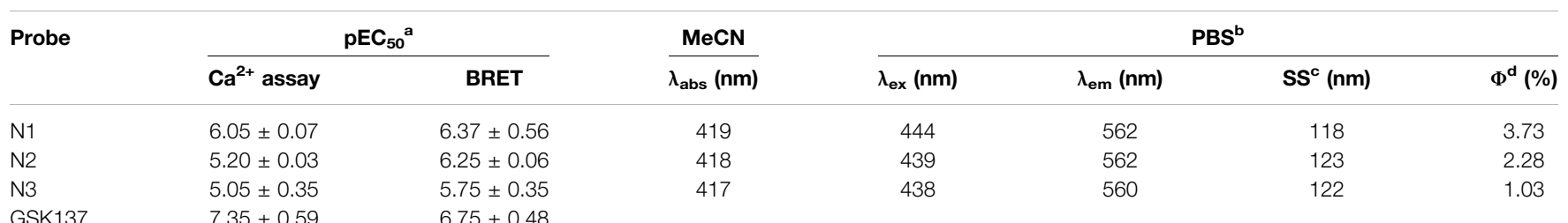




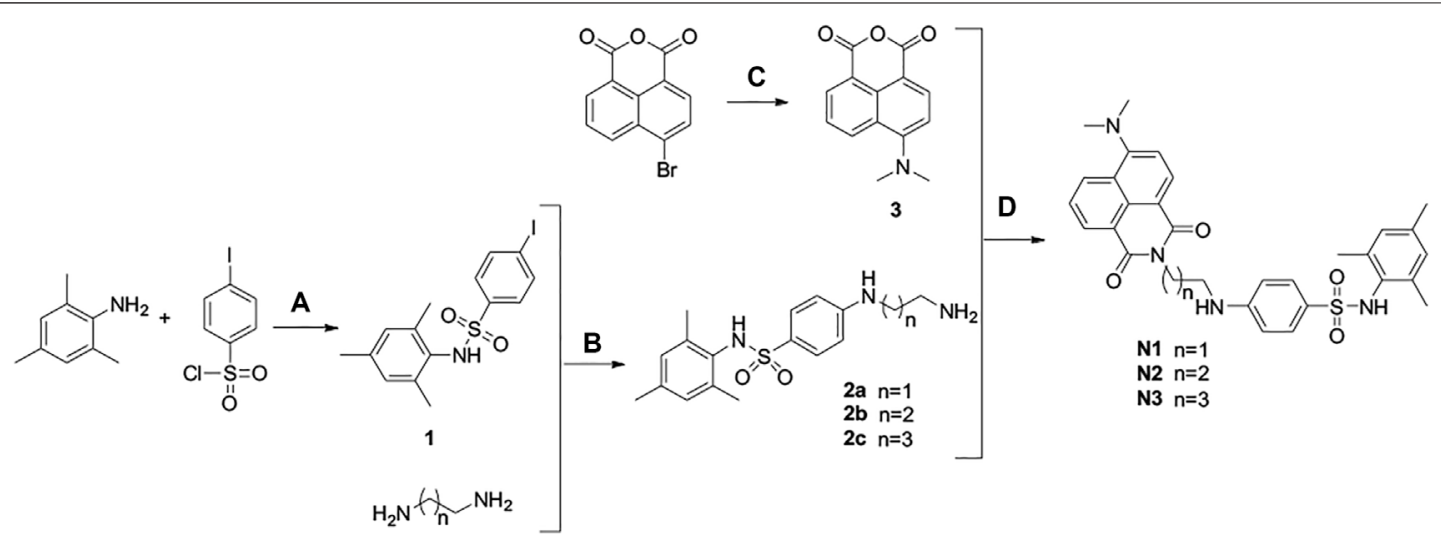

SCHEME 3 | Synthesis of ligands N1-N3. Reaction conditions and reagents: (a) pyridine, dichloromethane, $6^{\circ} \mathrm{h}$; (b) $\mathrm{Cul}, \mathrm{N}_{2}, 100^{\circ} \mathrm{C}, 16^{\circ} \mathrm{h}$; (c) $\mathrm{DCM}, \mathrm{CuSO}_{4} \cdot 5 \mathrm{H}_{2} \mathrm{O}$, DMF, $150^{\circ} \mathrm{C}, 12^{\circ} \mathrm{h}$; (d) absolute ethanol, $80^{\circ} \mathrm{C}, 7 \mathrm{~h}$.

results display that the fluorescence intensity surges with increasing concentration. Besides, the fluorescence spectra of fluorescent ligands were determined in four different polar solvents $\left(\mathrm{H}_{2} \mathrm{O}, \mathrm{DMSO}, \mathrm{EA}, \mathrm{MeCN}\right)$. The results indicate that when the probe is in a high-polar solvent $\left(\mathrm{H}_{2} \mathrm{O}\right)$, the fluorescence is quenched, and the fluorescence intensity is weak. When the probe is in a low polar solvent $(\mathrm{MeCN})$, its fluorescence intensity increases (Supplementary Figures S4-S6). Consequently, these fluorescent ligands can be used as environmentally sensitive smallmolecule fluorescent ligands. The cell-based experimental results indicate that the intensity of probe $\mathrm{N} 1$ is much greater than that of N2 and N3. With the increasing carbon chain length, the brightness exhibited a significant weakening trend. The reason of this phenomenon is that the increasing chain length tends to extend to the hydrophilic solvent area, which quenches the fluorescence and causes the fluorescence to weaken. The brightness of HEK293 cells was significantly greater than that of PC-3 cells at the same concentration (Supplementary Figures S8-S10).

The reported agonist GSK134647A was selected as the positive control in both the GPR120 $\mathrm{Ca}^{2+}$ assay and the BRET activity assay. The results of the $\mathrm{Ca}^{2+}$ flow assay $\left(\mathrm{pEC}_{50}: 7.35 \pm 0.59\right.$ ) and the BRET activity tests $\left(\mathrm{pEC}_{50}: 6.75 \pm 0.48\right)$ were within acceptable ranges, and as a result, these two methods were used to evaluate the probes we developed.

The experimental results presented that the short linker in fluorescent ligand may contribute to bioactivity (Table 1), in which probe $\mathrm{N} 1$ has high activity up to the positive control GSK134647A. In the GPR40 $\mathrm{Ca}^{2+}$ activity test, the reported agonist TAK875 was selected as a control. (Li et al., 2017) In brief, the $\mathrm{Ca}^{2+}$ response to GPR40 of probe N1 was much lower than that of TAK875, which proved that ligand N1 had a particular selectivity for GPR120 (Supplementary Figure S13).

\subsection{Bioluminescence Resonance Energy Transfer Experiments With Fluorescent Ligands}

Rluc was selected as a bioluminescence donor in the BRET experiments because the excitation spectrum of naphthalimide probes and the Rluc's emission spectrum are close to the ideal overlap. We selected the most potent probe $\mathrm{N} 1$ to conduct BRET experiments (Jenkins et al., 2010; Hansen et al., 2017)

\subsubsection{Bioluminescence Resonance Energy Transfer Saturation Experiment of Probe N1}

The specific and non-specific curves of the compound show that as the concentration increases, the compound binds nonspecifically to the target and affects the experimental results (Figure 1A). The $\mathrm{K}_{\mathrm{d}}$ value of $\mathrm{N} 1$ was calculated to be $1.12 \pm$ $0.6 \mu \mathrm{M}$. When the concentration of $\mathrm{N} 1$ is less than $2.76 \mu \mathrm{M}$, the non-specific binding of N1 to the target can be ignored. In the BRET competition experiment, the maximum concentration of probe N1 did not exceed $1000 \mathrm{nM}$, so it proved that the probe's non-specific binding did not affect the results of the BRET competition experiment.

\subsubsection{Bioluminescence Resonance Energy Transfer Kinetic Experiment of Probe N1}

Kinetic experiments indicate the rate of binding and dissociation of N1 to GPR120. The experimental results showed that the binding of N1 to GPR120 reached saturation within $6 \mathrm{~min}$. After adding excess positive drug GSK137647A, compound N1 gradually dissociated from GPR120 and reached a stable state at $30 \mathrm{~min}$. The kinetic binding experiment establishes that offrate $\mathrm{k}_{\text {off }}=0.068 \mathrm{~min}^{-1}$, on-rate $\mathrm{k}_{\text {on }}=249000 \mathrm{~min}^{-1} \mathrm{M}^{-1}$, and $\mathrm{K}_{\mathrm{d}}=$ $273 \mathrm{nM}$, respectively (Figure 1B).

The difference of $K_{d}$ values obtained by the BRET saturation experiment and the kinetic experiment is less than 10 times, which can be mutually verified. The experimental results prove the affinity of the fluorescent ligand N1 for GPR120.

\subsubsection{Bioluminescence Resonance Energy Transfer Competitive Experiment of Probe N1 (Preliminary Screening Method)}

Different concentrations of GPR120 ligands can compete with N1 at the target site. As the BRET value decreases, the competition curve can be obtained to evaluate the activity of ligands (Figure 2). 

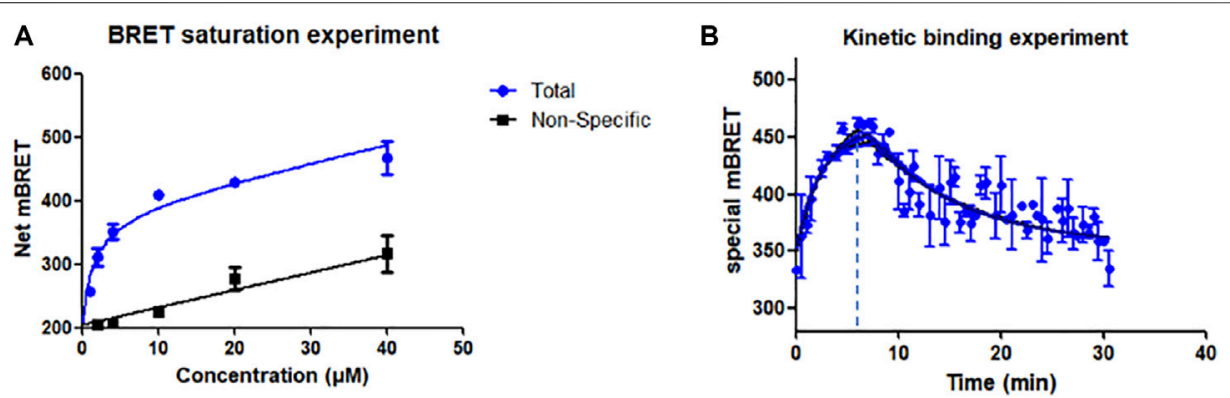

FIGURE 1 | (A) Saturation experiment of the affinity of probe N1 at GPR120. $15 \mu$ M GSK134647A co-incubation for non-specific experiments; (B) Kinetic binding experiments of $\mathrm{N1} ; 6 \mathrm{~min}$ after the addition of fluorescent probe $(500 \mathrm{nM})$, GSK137647A (10 $\mu \mathrm{M})$ was added to make the probe dissociate from GPR120.
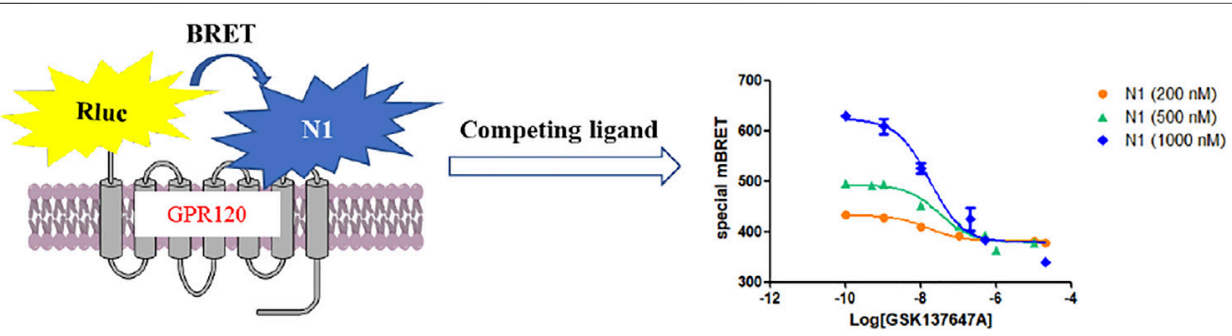

FIGURE 2 | The mechanism of BRET competitive experiment.

TABLE 2 | Comparison of BRET results to reference data

\begin{tabular}{lccc} 
Compd & $\mathbf{p K}_{\mathbf{i}}^{\mathbf{a}}$ (N1) & $\mathbf{p E C}_{\mathbf{5 0}}{ }^{\mathbf{b}} \mathbf{( C a}^{\mathbf{2 +}}$ assay) & $\mathbf{p E C}_{\mathbf{5 0}}{ }^{\mathbf{c}}$ (Literature) \\
\hline GSK137647A & $6.96 \pm 0.32$ & $7.35 \pm 0.59$ & $6.30 \pm 0.2^{16}$ \\
TUG-891 & $7.06 \pm 0.35$ & $7.42 \pm 0.15$ & $7.02 \pm 0.09^{15}$ \\
AH-7614 & $<4.5$ & $<4.5$ & $<4.5^{16}$
\end{tabular}

${ }^{a} \mathrm{PK}_{i}$ is the result of BRET competitive binding experiments. Probe $\mathrm{N} 1$ is $400 \mathrm{nM}$. ${ }^{b} p E C_{50}\left(\mathrm{Ca}^{2+}\right.$ assay) is the result of the $\mathrm{Ca}^{2+}$ assay.

${ }^{c} \mathrm{pEC} \mathrm{C}_{50}$ is the theoretical value reported.

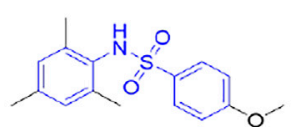

GSK137647A

FFA4 Human $\mathrm{pEC}_{50}: 6.3(0.17)$

FFA1 Human $\mathrm{pEC}_{50}:<4.5$

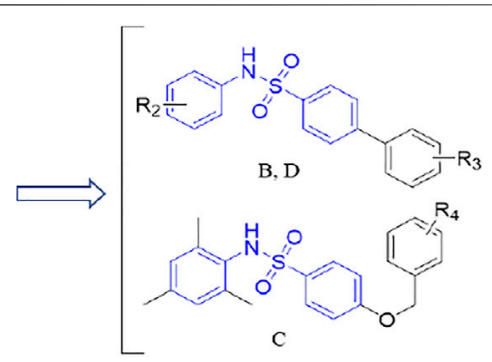

FIGURE 3 | The design strategy of GPR120 small-molecule agonists.

The activities of the GPR120 agonists (GSK134647A, TUG891) and antagonist (AH-7614) measured by BRET competitive binding experiments were similar to those obtained by $\mathrm{Ca}^{2+}$ assay, and the theoretical values reported (Table 2, Supplementary Figure S11). (Moniri, 2016) In BRET competitive experiments of probes with different concentrations (Figure 2, Supplementary
Figure S12), when probe N1 had a greater concentration, the BRET value obtained was higher, consistent with the principle of BRET activity determination.

BRET competition experiments display that probe $\mathrm{N} 1$ can construct a GPR120 agonist activity screening method at $400 \mathrm{nM}$ and will be applied to screen the modified agonists.

\subsection{The Design Strategy of Modified Compounds}

As mentioned earlier, the sulfonamide agonist GSK137657A has high selectivity and activity of promoting insulin secretion. We found that its phenyl ring conjugated structure is related to the selectivity of GPR120. Based on this, starting from the core structure of GSK137647A, three new types of agonists were developed herein (Figure 3; Supplementary Table S1; Scheme 4).

\subsection{The Biological Activity of Modified Compounds}

The survival rate of modified compounds is greater than $50 \%$ at $50 \mu \mathrm{M}$, and in subsequent cell experiments, the concentration of the compounds does not exceed $20 \mu \mathrm{M}$, it is proved that all compounds have acceptable cytotoxicity (Supplementary Figure S14).

\subsubsection{Preliminary Screening}

We conducted preliminary activity screening of the modified 3 series (B series; C series; D series) of small-molecule agonists 


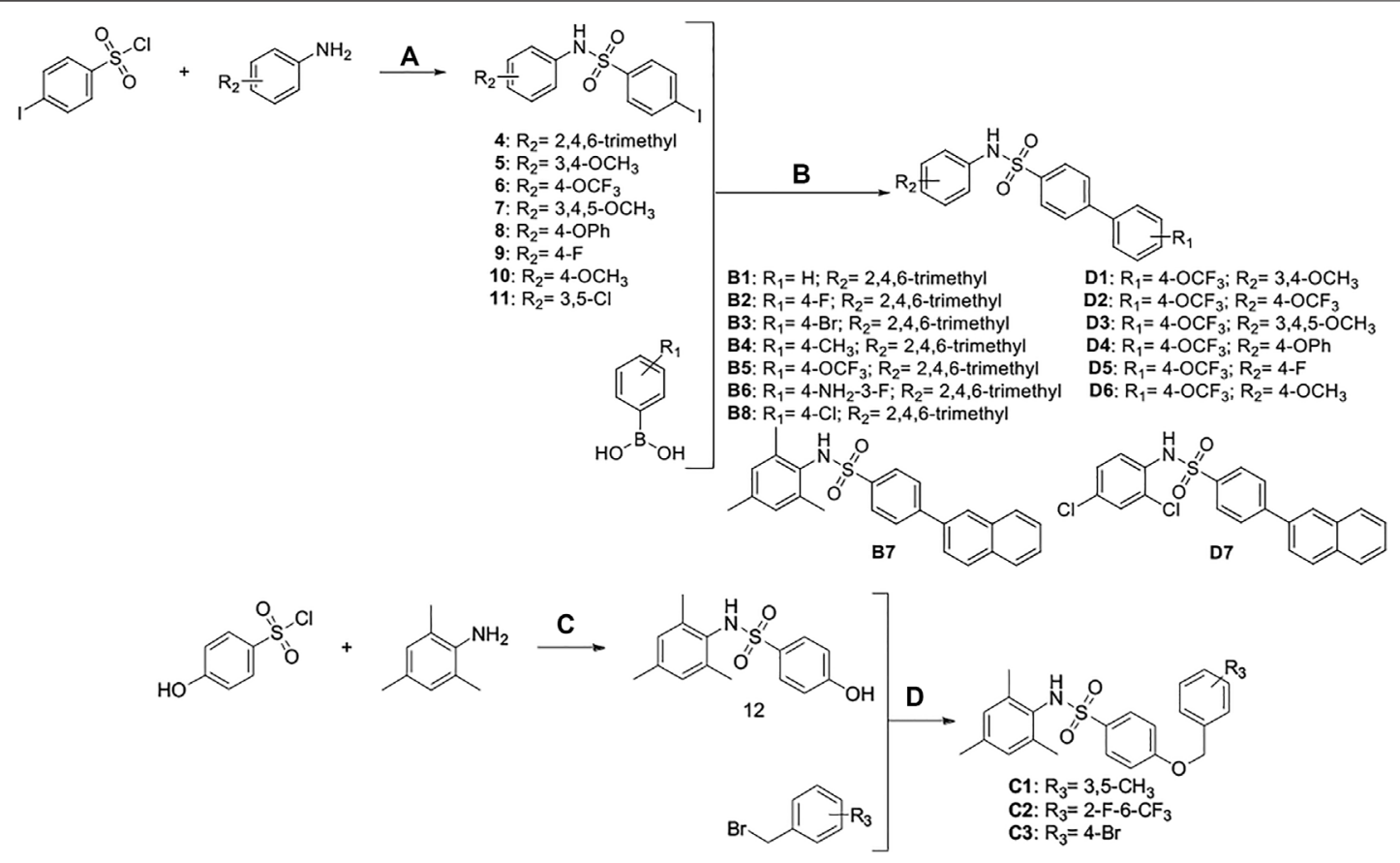

SCHEME 4 |Synthesis and preparation of the modified compounds (B1-B8; C1-C3; D1-D7). Reaction conditions and reagents: (a) pyridine, dichloromethane, 6 h; (b) 1,1'- $\mathrm{PdCl}_{2}(\mathrm{dppf}), \mathrm{K}_{2} \mathrm{CO}_{3}, \mathrm{~N}_{2}, 80^{\circ} \mathrm{C}, \mathrm{EtOH}, 1 \mathrm{~h}$; (c) pyridine, dichloromethane, $6 \mathrm{~h}$; (d) $\mathrm{K}_{2} \mathrm{CO}_{3}, \mathrm{MeCN}, 7 \mathrm{~h}$.

based on the established BRET screening method. The results present that the inhibition rates of compounds B5-7, D5, and D7 are higher than GSK137647A (Figure 4). It is proved that based on increasing the conjugated structure, the introduction of electronegative $\mathrm{F}$ atoms can increase the biological activity of compounds, so we have conducted in-depth research on these 5 compounds (B5, B6, B7, D5, D7).

\subsubsection{In vitro Activity Test of Preferred Compounds}

The $\mathrm{Ca}^{2+}$ flow and BRET assays were performed on these five compounds (Table 3), and the results revealed that compound D5 had the best activity, and the $\mathrm{Ca}^{2+}$ response value of five compounds to GPR40 was much lower than TAK875 (Figure 5A). Among them, D5 is relatively biased towards the Gq pathway to promote the secretion of GLP-1 (Figure 5B). In consequence, we chose D5 for the animal blood glucose experiments.

\subsection{Competitive Cell Imaging of D5 and Fluorescent Ligand N1}

The experimental results show (Figure 5C) that only incubating N1 with cells can emit strong fluorescence. However, after incubating an excessive amount of D5 with N1, the fluorescence intensity decreased significantly (Figure 5D), which to a certain extent indicates the binding ability of compound D5 and GPR120.

\subsection{The Animal Blood Glucose Experiments}

Compared with GSK137647A, compound D5 can achieve the same blood glucose-lowering level at a low dose $(10 \mathrm{mg} / \mathrm{kg})$, while it can reach a higher blood-glucose-lowering level at a high dose $(30 \mathrm{mg} / \mathrm{kg}$ ) (Figures 6A,B). Simultaneously, the glucose tolerance test (Figures 6C,D) further proved the glucoselowering ability of $\mathrm{D} 5$ in $\mathrm{db} / \mathrm{db}$ mice. D5 at a low dose $(10 \mathrm{mg} / \mathrm{kg})$ reduced blood glucose $\mathrm{AUC}_{0-120 \mathrm{~min}}$ by $15.3 \%$; it reduced blood glucose $\mathrm{AUC}_{0-120 \text { min }}$ by $30.3 \%$ at a high dose $(30 \mathrm{mg} / \mathrm{kg})$, which was higher than GSK137647A $\left(\mathrm{AUC}_{0-120} \mathrm{~min}\right.$ decreased by $19.3 \%)$.

The weight changes showed that the weight of the low-dose administration group $(10 \mathrm{mg} / \mathrm{kg})$ reached a stable level in the fourth week (Supplementary Figure S15); the weight of the highdose administration group (30 mg/kg) decreased in the fourth week, which further proved the therapeutic effect of compound D5 on T2DM model mice.

\section{CONCLUSION AND PERSPECTIVE}

In this study, we designed and synthesized a series of fluorescent ligands with good fluorescence performance and excellent biological activity to GPR120. The representative fluorescent ligand $\mathrm{N} 1$ can be successfully used to localize and visualize GPR120 at the nanomolar level. Subsequently, we utilized BRET competitive experiment-based fluorescent ligand $\mathrm{N} 1$ as a fluorescent competitive substrate to establish a method that can successfully screen small-molecule agonists of GPR120. Then, we modified 3 series of small-molecule agonists based on the core of GSK137647A and conducted preliminary activity screening through the BRET activity screening method we established. Further pharmacological tests were conducted on compounds 


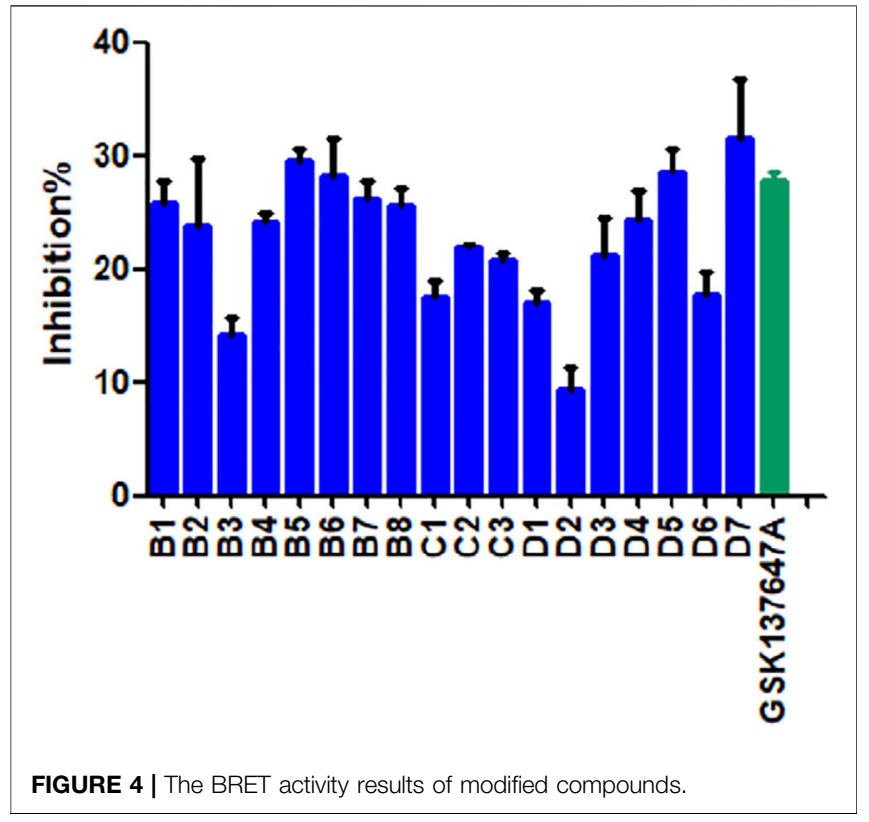

(B5, B6, B7, D5, D7) with good preliminary screening results. Compound D5 was identified as a potent GPR120 agonist with high activity and selectivity, importantly, which exhibited a significant glucose-lowering effect in vivo. The structureactivity relationship shows that the introduction of biphenyl conjugated structure and the electronegative $\mathrm{F}$ atom to the pharmacophore can increase the biological activity of the compound. This study demonstrates the potential of the fluorescent ligand-based BRET method in the screening of small-molecule agonists of GPR120. It is anticipated that such an activity screening strategy could be similarly extended to other targets of GPCRs to provide a novel method.

\section{EXPERIMENTAL SECTION}

\subsection{Chemistry} 4.1.1 Reagents

All reagents are chemical pure or analytical pure, and the water used in chemical experiments is distilled water. Unless otherwise specified, reagents and solvents were used without further

TABLE 3 | The pharmacological activities of selected compounds.

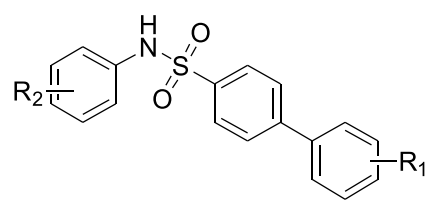

\begin{tabular}{|c|c|c|c|c|c|c|}
\hline No. & Structure & 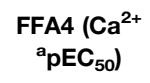 & $\mathrm{bE}_{\max }$ & $\begin{array}{c}\text { FFA4 } \\
\left(\beta \text {-arrestin2 }{ }^{\mathrm{a}} \mathrm{pEC}_{50}\right)\end{array}$ & ${ }^{b} E_{\max }$ & $\begin{array}{c}\text { FFA1 }\left(\mathrm{Ca}^{2+}\right. \\
\left.{ }^{\mathrm{a}} \mathrm{pEC} \mathrm{C}_{50}\right)\end{array}$ \\
\hline B5 & & $7.09 \pm 0.30$ & 1.27 & $7.36 \pm 0.02$ & 0.790 & $<4.3$ \\
\hline B6 & & $6.69 \pm 0.58$ & 1.25 & $6.88 \pm 0.33$ & 0.881 & $<4.3$ \\
\hline B7 & & $6.86 \pm 0.53$ & 0.285 & $7.71 \pm 0.66$ & 0.894 & $<4.3$ \\
\hline D5 & & $8.27 \pm 0.44$ & 1.22 & $7.46 \pm 0.21$ & 1.12 & $<4.3$ \\
\hline D7 & & $6.89 \pm 0.14$ & 0.752 & $7.78 \pm 0.01$ & 1.17 & $<4.3$ \\
\hline
\end{tabular}

${ }^{a} \mathrm{pEC}_{50}$ is a biological activity value obtained from the $\mathrm{Ca}^{2+}$ ion activity test and the $\beta$-arrestin-2 activity test method.

${ }^{b} E_{\text {max }}$ : The positive compound GSK137647A $\left(\mathrm{Ca}^{2+} p E C_{50}: 7.35 \pm 0.59 ; \beta\right.$-arrestin2: $\left.6.75 \pm 0.48\right)$ was used as a standard. 

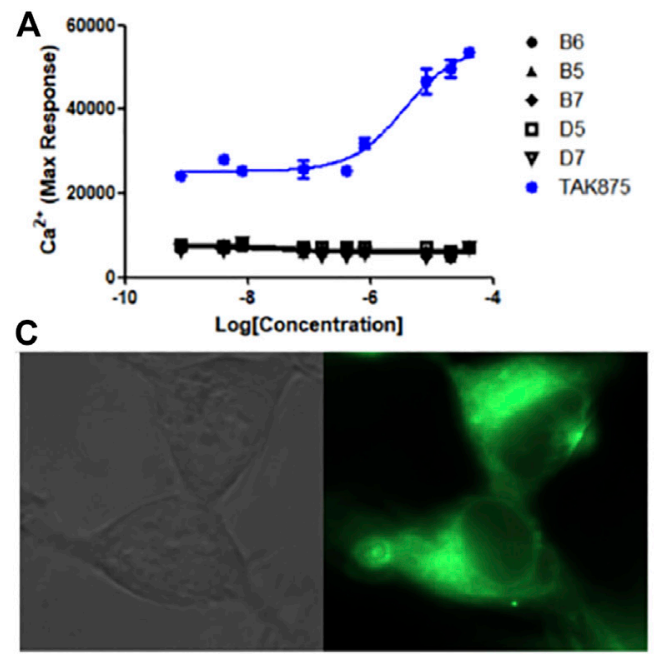
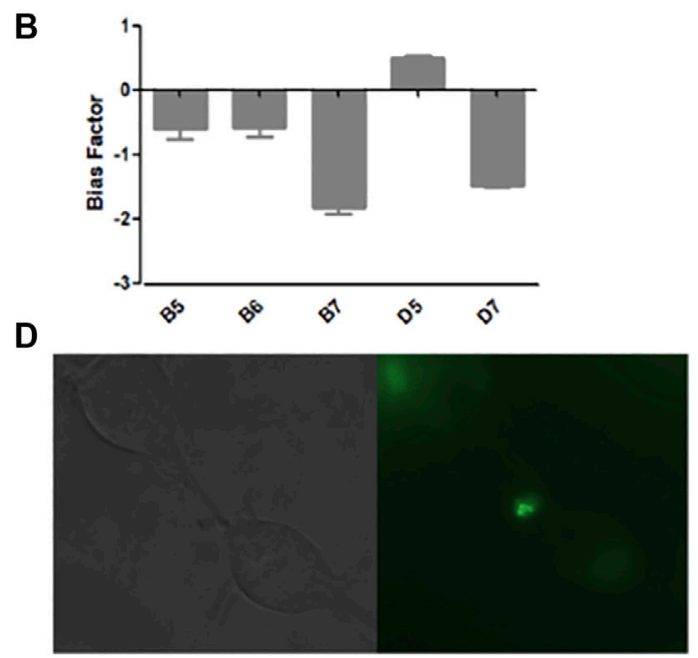

FIGURE 5 | (A) The $\mathrm{Ca}^{2+}$ response of modified compounds (B5, B6, B7, D5, D7, TAK875) against GPR40. TAK875 is a positive GPR40 agonist reported in the literature; (B) The bias factor of compounds (B5, B6, B7, D5, D7); Exposure time was 500 ms; GFP channel; $\times 63$ lens magnification. (C) Imaging result of N1 (0.5 $\mu$ M) in HEK293 cells (stably transfected with GPR120); (D) Imaging result of N1 (0.5 MM) and D5 (10 $\mu$ M) in HEK293 cells (stably transfected with GPR120).

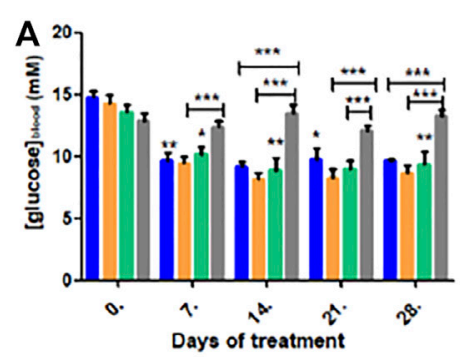

C

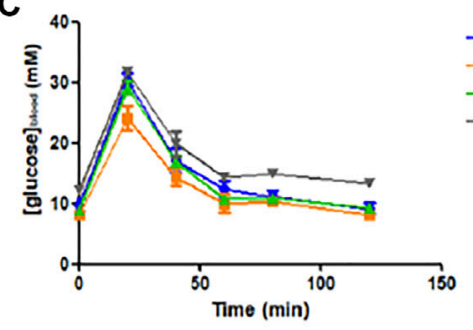

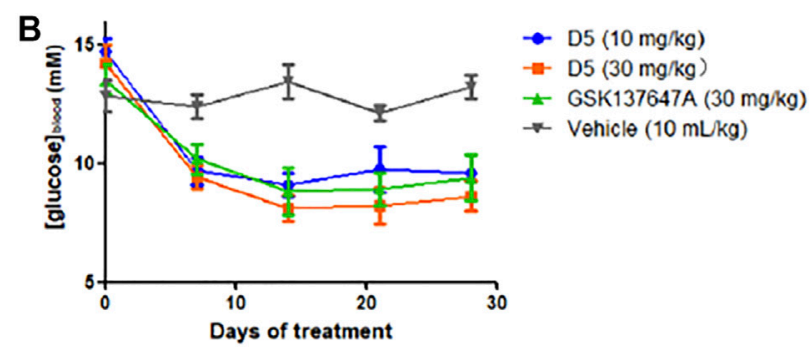

D

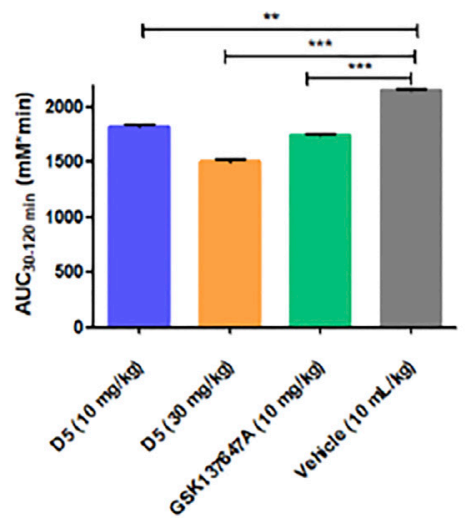

FIGURE 6 | (A, B) The fasting blood glucose values of db/db mice after 4 weeks of continuous administration. ${ }^{* \star \star} p \leq 0.001 ;{ }^{* \star} p \leq 0.01 ;{ }^{*} p \leq 0.05$; (C, D) Blood glucose at a different time $(5,10,30,60,120 \mathrm{~min})$ after oral administration of glucose in mice.

purification. The melting points were determined on an RY-1G melting point apparatus (uncorrected temperature before use). NMR spectra were obtained on a Bruker AV-400 spectrometer with $400 \mathrm{MHz}$ for ${ }^{1} \mathrm{H}$ NMR and $100 \mathrm{MHz}$ for ${ }^{13} \mathrm{C}$ NMR. Mass spectra (ESI mode) and high-resolution mass spectra (HR-MS) were conducted in the Analysis and Test Center of Shandong
University, Jinan, China. The HPLC analysis of the compounds was performed on Agilent Technologies 1260 series highperformance liquid chromatography (Agilent Technologies Inc., Santa Clara, CA, United States) using a C18 reversedphase column $(250 \mathrm{~mm} \times 4.6 \mathrm{~mm}, 5 \mu \mathrm{m}$, Phenomenex Inc., Torrance, CA, United States). 


\subsubsection{Synthesis Steps}

\subsubsection{4-iodo-N-mesitylbenzenesulfonamide (1)}

2,4,6-trimethylaniline $(232.07 \mu \mathrm{l}, 1.65 \mu \mathrm{mol})$ and pyridine $(399.46 \mu \mathrm{l}, 4.96 \mu \mathrm{mol})$ were added to $10 \mathrm{ml}$ of dry dichloromethane, then $p$-iodobenzene sulfonyl chloride (500 mg, $1.65 \mu \mathrm{mol}$ ) dissolved in a small amount of dichloromethane was slowly dropped into the above solution. After stirring at room temperature for $6 \mathrm{~h}$, added $50 \mathrm{ml}$ dichloromethane $(2 \times 20 \mathrm{ml})$ and $1 \mathrm{M}$ hydrochloric acid $(2 \times$ $10 \mathrm{ml}$ ) to the reaction solution for extraction, then combined the organic phases, washed with distilled water twice, and then washed with saturated brine, dried over anhydrous sodium sulfate, filtered, concentrated under reduced pressure. The crude product was purified by silica gel column chromatography with dichloromethane and methanol to afford a white solid. Yield: $520 \mathrm{mg}, 78 \% .{ }^{1} \mathrm{H}$ NMR (400 MHz, DMSO) $\delta$ $9.34(\mathrm{~s}, 1 \mathrm{H}), 7.97$ (d, $J=7.6 \mathrm{~Hz}, 2 \mathrm{H}), 7.41(\mathrm{~d}, J=7.7 \mathrm{~Hz}, 2 \mathrm{H}), 6.83$ (s, 2H), 2.19 (s, 3H), 1.90 (s, 6H). ESI-MS: m/z [M - H] ${ }^{-}$calcd for $\mathrm{C}_{15} \mathrm{H}_{15} \mathrm{INO}_{2} \mathrm{~S}^{-} 400.3$, found 400.2 .

\subsubsection{4-((2-aminoethyl)amino)-N- mesitylbenzenesulfonamide (2a)}

Intermediate $1(100 \mathrm{mg}, 249.21 \mu \mathrm{mol})$ and cuprous iodide (4.75 $\mathrm{mg}, 24.92 \mu \mathrm{mol})$ were added into ethylenediamine $(1.66 \mathrm{ml}$, $24.92 \mathrm{mmol})$ firstly; then the solution was heated to $100{ }^{\circ} \mathrm{C}$ for $16 \mathrm{~h}$. After the solution was cooled to room temperature, concentrated most of the solution under reduced pressure at $70^{\circ} \mathrm{C}$. The solution was extracted with saturated sodium bicarbonate solution $(3 \times 40 \mathrm{ml})$ and dichloromethane $(3 \times$ $40 \mathrm{ml})$, then it was washed with distilled water $(2 \times 20 \mathrm{ml})$ and saturated brine $(3 \times 40 \mathrm{ml})$. After that, the organic layer was combined and dried over sodium sulfate, filtered, concentrated under reduced pressure. The crude product was purified by silica gel column chromatography with dichloromethane and methanol and a small amount of triethylamine to afford a white solid. Yield: $60 \mathrm{mg}, 72 \%, \mathrm{mp}$ : $148-149^{\circ} \mathrm{C} .{ }^{1} \mathrm{H}$ NMR $\left(400 \mathrm{MHz}, \mathrm{CDCl}_{3}\right) \delta 7.47(\mathrm{~d}, J=8.3 \mathrm{~Hz}$, $1 \mathrm{H}), 6.82(\mathrm{~s}, 1 \mathrm{H}), 6.54(\mathrm{~d}, J=8.3 \mathrm{~Hz}, 1 \mathrm{H}), 3.20(\mathrm{~s}, 1 \mathrm{H}), 2.99(\mathrm{~d}, J=$ $5.2 \mathrm{~Hz}, 1 \mathrm{H}), 2.24(\mathrm{~s}, 2 \mathrm{H}), 2.04(\mathrm{~s}, 3 \mathrm{H})$. ESI-MS: $\mathrm{m} / \mathrm{z}[\mathrm{M}+\mathrm{H}]^{+}$ calcd for $\mathrm{C}_{17} \mathrm{H}_{24} \mathrm{~N}_{3} \mathrm{O}_{2} \mathrm{~S}^{+}$334.5, found 334.4.

\subsubsection{4-((3-aminopropyl)amino)-N- mesitylbenzenesulfonamide (2b)}

Intermediate $1(100 \mathrm{mg}, 249.21 \mu \mathrm{mol})$ and cuprous iodide $(4.75 \mathrm{mg}, 24.92 \mu \mathrm{mol})$ were added into 1,3-propylene diamine $(2.08 \mathrm{ml}, 24.92 \mathrm{mmol})$ firstly; then the solution was heated to $100^{\circ} \mathrm{C}$ for $20 \mathrm{~h}$. After the solution was cooled to room temperature, most of the solution was concentrated under reduced pressure at $70^{\circ} \mathrm{C}$. The solution was extracted with saturated sodium bicarbonate solution $(3 \times 40 \mathrm{ml})$ and dichloromethane $(3 \times 40 \mathrm{ml})$, and it was washed with distilled water $(2 \times 20 \mathrm{ml})$ and saturated brine $(3 \times 40 \mathrm{ml})$. After that, the organic layer was combined and dried over sodium sulfate, filtered, concentrated under reduced pressure. The crude product was purified by silica gel column chromatography with dichloromethane and methanol and a small amount of triethylamine to afford a white solid. Yield: $48 \mathrm{mg}, 55 \%, \mathrm{mp}$ :
151-152 ${ }^{\circ} \mathrm{C} .{ }^{1} \mathrm{H}$ NMR $\left(400 \mathrm{MHz}, \mathrm{CDCl}_{3}\right) \delta 7.46(\mathrm{~d}, J=8.2 \mathrm{~Hz}$, $1 \mathrm{H}), 6.81(\mathrm{~s}, 1 \mathrm{H}), 6.51(\mathrm{~d}, J=8.2 \mathrm{~Hz}, 1 \mathrm{H}), 3.25(\mathrm{t}, J=6.3 \mathrm{~Hz}, 1 \mathrm{H})$, $2.89(\mathrm{t}, J=6.3 \mathrm{~Hz}, 1 \mathrm{H}), 2.24(\mathrm{~s}, 1 \mathrm{H}), 2.04(\mathrm{~s}, 3 \mathrm{H}), 1.82-1.73(\mathrm{~m}$, 1H). ESI-MS: $\mathrm{m} / \mathrm{z}[\mathrm{M}+\mathrm{H}]^{+}$calcd for $\mathrm{C}_{18} \mathrm{H}_{26} \mathrm{~N}_{3} \mathrm{O}_{2} \mathrm{~S}^{+} 348.5$, found 348.5 .

\subsubsection{4-((4-aminobutyl)amino)-N- mesitylbenzenesulfonamide (2c)}

Intermediate $1(100 \mathrm{mg}, 249.21 \mu \mathrm{mol})$ and cuprous iodide $(4.75 \mathrm{mg}, 24.92 \mu \mathrm{mol})$ were added into 1,4-butanediamine $(2.51 \mathrm{ml}, 24.92 \mathrm{mmol})$ firstly; then the solution was heated to $100^{\circ} \mathrm{C}$ for $20 \mathrm{~h}$. After the solution was cooled to room temperature, most of the solution was concentrated under reduced pressure at $70^{\circ} \mathrm{C}$. The solution was extracted with saturated sodium bicarbonate solution $(3 \times 40 \mathrm{ml})$ and dichloromethane $(3 \times 40 \mathrm{ml})$, and it was washed with distilled water $(2 \times 20 \mathrm{ml})$ and saturated brine $(3 \times 40 \mathrm{ml})$. After that, the organic layer was combined and dried over sodium sulfate, filtered, concentrated under reduced pressure. The crude product was purified by silica gel column chromatography with dichloromethane and methanol and a small amount of triethylamine to afford a white solid. Yield: $40 \mathrm{mg}, 44 \%, \mathrm{mp}$ : $152-153^{\circ} \mathrm{C} .{ }^{1} \mathrm{H}$ NMR $\left(400 \mathrm{MHz}, \mathrm{CDCl}_{3}\right) \delta 7.45(\mathrm{~d}, J=8.3 \mathrm{~Hz}$, $1 \mathrm{H}), 6.80(\mathrm{~s}, 1 \mathrm{H}), 6.49(\mathrm{~d}, J=8.4 \mathrm{~Hz}, 1 \mathrm{H}), 5.30(\mathrm{~s}, 1 \mathrm{H}), 3.13(\mathrm{t}, J=$ $6.4 \mathrm{~Hz}, 1 \mathrm{H}), 2.76(\mathrm{t}, J=6.4 \mathrm{~Hz}, 1 \mathrm{H}), 2.23(\mathrm{~s}, 2 \mathrm{H}), 2.03(\mathrm{~s}, 3 \mathrm{H})$ 1.70-1.62 (m, 1H), 1.60-1.48 (m, 1H). ESI-MS: m/z [M - H] calcd for $\mathrm{C}_{19} \mathrm{H}_{26} \mathrm{~N}_{3} \mathrm{O}_{2} \mathrm{~S}^{-} 360.5$, found 360.5 .

\subsubsection{6-(Dimethylamino)-1H,3H-benzo[de]isochromene- 1,3-dione (3)}

To a solution of 4-bromo-1,8-naphthalenedicarboxylic anhydride $(1.5 \mathrm{~g}, 5.41 \mathrm{mmol})$ in DMF $(40 \mathrm{ml})$ was added dimethylamine aqueous solution $(2.0 \mathrm{~g}, 43.2 \mathrm{mmol})$ and copper sulfate pentahydrate $(130.26 \mathrm{mg}, 541.37 \mu \mathrm{mol})$. The reaction mixture was heated at $150^{\circ} \mathrm{C}$ for $12 \mathrm{~h}$. The temperature was then allowed to reach room temperature. The reaction mixture was concentrated under reduced pressure at $70^{\circ} \mathrm{C}$, diluted with ice ethanol, and filtered. The filtrate was dried to give intermediate 1 as a yellow solid. Yield: $1.10 \mathrm{~g}, 84 \%$, m.p. $191-192^{\circ} \mathrm{C} .{ }^{1} \mathrm{H}$ NMR $\left(400 \mathrm{MHz}, \mathrm{DMSO}-d_{6}\right) \delta 8.59(\mathrm{~d}, J=8.5 \mathrm{~Hz}, 1 \mathrm{H}), 8.46(\mathrm{~d}, J=7.2$ $\mathrm{Hz}, 1 \mathrm{H}), 8.32(\mathrm{~d}, J=8.3 \mathrm{~Hz}, 1 \mathrm{H}), 7.76(\mathrm{t}, 1 \mathrm{H}), 7.20(\mathrm{~d}, J=8.4 \mathrm{~Hz}$, $1 \mathrm{H}), 3.17$ (s, 6H). ESI-MS: $\mathrm{m} / \mathrm{z}[\mathrm{M}-\mathrm{H}]^{-}$calcd for $\mathrm{C}_{19} \mathrm{H}_{26} \mathrm{~N}_{3} \mathrm{O}_{2} \mathrm{~S}^{-}$ 360.5 , found 360.5 .

\subsubsection{4-((2-(6-(Dimethylamino)-1,3-dioxo-1H-benzo[de] isoquinolin-2(3H)-yl)ethyl)amino)-N- mesitylbenzenesulfonamide (N1)}

Intermediate $1 \mathrm{a}(50 \mathrm{mg}, 149.95 \mu \mathrm{mol})$ and intermediate $1(39.79$ $\mathrm{mg}, 164.94 \mu \mathrm{mol}$ ) were added to $15 \mathrm{ml}$ of absolute ethanol, then the reaction solution was heated to $80^{\circ} \mathrm{C}$ for $7 \mathrm{~h}$. After the solution was cooled to room temperature, concentrated most of the solution under reduced pressure at $40^{\circ} \mathrm{C}$. The crude product was purified by silica gel column chromatography with dichloromethane and methanol to afford a yellow solid. Yield: $62 \mathrm{mg}, 74 \%$, m.p. $230-231^{\circ} \mathrm{C}$. ${ }^{1} \mathrm{H}$ NMR $\left(400 \mathrm{MHz}, \mathrm{CDCl}_{3}\right) \delta 8.58(\mathrm{~d}, J=7.2 \mathrm{~Hz}$, $1 \mathrm{H}), 8.47(\mathrm{t}, 2 \mathrm{H}), 7.67(\mathrm{t}, J=7.7 \mathrm{~Hz}, 1 \mathrm{H}), 7.41(\mathrm{~d}, J=8.2 \mathrm{~Hz}, 2 \mathrm{H})$, $7.12(\mathrm{~d}, J=8.2 \mathrm{~Hz}, 1 \mathrm{H}), 6.77(\mathrm{~s}, 2 \mathrm{H}), 6.55(\mathrm{~d}, J=8.3 \mathrm{~Hz}, 2 \mathrm{H}), 5.71$ 
(s, 1H), $5.03(\mathrm{~s}, 1 \mathrm{H}), 4.50(\mathrm{t}, J=5.6 \mathrm{~Hz}, 2 \mathrm{H}), 3.60-3.50(\mathrm{~m}, 2 \mathrm{H}), 3.13$ $(\mathrm{s}, 6 \mathrm{H}), 2.22(\mathrm{~s}, 3 \mathrm{H}), 1.98(\mathrm{~s}, 6 \mathrm{H}) .{ }^{13} \mathrm{C}$ NMR (100 MHz, DMSO) $\delta$ $164.43,163.63,157.02,152.30,137.85,136.30,132.98,132.08$, $131.67,131.10,130.21,129.32,128.80,127.90,125.46,124.65$, $122.78,113.70,113.43,111.36,44.92,38.60,20.89,18.82$. ESIHRMS: $\mathrm{m} / \mathrm{z}[\mathrm{M}+\mathrm{H}]^{+}$calcd for $\mathrm{C}_{31} \mathrm{H}_{33} \mathrm{~N}_{4} \mathrm{O}_{4} \mathrm{~S}^{+}$557.2223, found 557.2215. HPLC, $t_{R}=13.564 \mathrm{~min}, 97.1 \%$ Purity, mobile phase: methanol-water $(75: 25, v / v), \lambda=280 \mathrm{~nm}$.

\subsubsection{4-((3-(6-(Dimethylamino)-1,3-dioxo-1H-benzo[de] isoquinolin-2(3H)-yl)propyl) \\ amino)-N-mesitylbenzenesulfonamide (N2)}

Intermediate $1 \mathrm{~b}(80 \mathrm{mg}, 230.23 \mu \mathrm{mol})$ and intermediate $1(55.54 \mathrm{mg}$, $230.23 \mu \mathrm{mol}$ ) were added to $15 \mathrm{ml}$ of absolute ethanol, then the reaction solution was heated to $80^{\circ} \mathrm{C}$ for $7 \mathrm{~h}$. After the solution was cooled to room temperature, concentrated most of the solution under reduced pressure at $40^{\circ} \mathrm{C}$. The crude product was purified by silica gel column chromatography with dichloromethane and methanol to afford a yellow solid. Yield: $46 \mathrm{mg}, 35 \%$, m.p. $103-104^{\circ} \mathrm{C} .{ }^{1} \mathrm{H}$ NMR $\left(400 \mathrm{MHz}, \mathrm{CDCl}_{3}\right) \delta 8.59(\mathrm{~d}, J=7.2 \mathrm{~Hz}$, $1 \mathrm{H}), 8.48(\mathrm{t}, J=8.4 \mathrm{~Hz}, 2 \mathrm{H}), 7.69(\mathrm{t}, J=7.7 \mathrm{~Hz}, 1 \mathrm{H}), 7.45(\mathrm{~d}, J=8.2$ $\mathrm{Hz}, 2 \mathrm{H}), 7.13(\mathrm{~d}, J=8.1 \mathrm{~Hz}, 1 \mathrm{H}), 6.82(\mathrm{~s}, 2 \mathrm{H}), 6.57(\mathrm{~d}, J=8.4 \mathrm{~Hz}, 2 \mathrm{H})$, $5.74(\mathrm{~s}, 1 \mathrm{H}), 5.00(\mathrm{~s}, 1 \mathrm{H}), 4.29(\mathrm{t}, J=6.4 \mathrm{~Hz}, 2 \mathrm{H}), 3.26-3.21(\mathrm{~m}, 2 \mathrm{H})$, 3.13 (s, 6H), 2.24 (s, 3H), 2.09-2.01 (m, 8H). ${ }^{13} \mathrm{C}$ NMR (100 MHz, DMSO- $\left.d_{6}\right) \delta 164.43,163.83,157.16,152.29,137.99,136.18,132.84$, $132.02,131.93,131.06,130.12,129.48,128.87,127.53,125.39,124.61$, $122.96,113.68,113.45,111.70,44.81,40.84,38.07,20.88,18.97$. ESIHRMS: $\mathrm{m} / \mathrm{z}[\mathrm{M}+\mathrm{H}]^{+}$calcd for $\mathrm{C}_{32} \mathrm{H}_{35} \mathrm{~N}_{4} \mathrm{O}_{4} \mathrm{~S}^{+}$571.2379, found 571.2376. HPLC, $t_{R}=8.047 \mathrm{~min}, 96.0 \%$ Purity, mobile phase: methanol-water $(75: 25, v / v), \lambda=280 \mathrm{~nm}$.

\subsubsection{4-((4-(6-(Dimethylamino)-1,3-dioxo-1H-benzo[de] isoquinolin-2(3H)-yl)butyl) \\ amino)-N-mesitylbenzenesulfonamide (N3)}

Intermediate $1 \mathrm{c}(30 \mathrm{mg}, 82.99 \mu \mathrm{mol})$ and intermediate $1(20.02 \mathrm{mg}$, $82.99 \mu \mathrm{mol})$ were added to $15 \mathrm{ml}$ of absolute ethanol, then the reaction solution was heated to $80^{\circ} \mathrm{C}$ for $7 \mathrm{~h}$. After the solution was cooled to room temperature, concentrated most of the solution under reduced pressure at $40^{\circ} \mathrm{C}$. The crude product was purified by silica gel column chromatography with dichloromethane and methanol to afford a yellow solid. Yield: $25 \mathrm{mg}, 51 \%$, m.p. 184-185 C. ${ }^{1} \mathrm{H}$ NMR $\left(400 \mathrm{MHz}, \mathrm{CDCl}_{3}\right) \delta 8.58$ (d, $J=7.2 \mathrm{~Hz}$, $1 \mathrm{H}), 8.47(\mathrm{t}, J=11.7,8.7 \mathrm{~Hz}, 2 \mathrm{H}), 7.67(\mathrm{t}, J=7.9 \mathrm{~Hz}, 1 \mathrm{H}), 7.43(\mathrm{~d}$, $J=8.1 \mathrm{~Hz}, 2 \mathrm{H}), 7.12(\mathrm{~d}, J=8.2 \mathrm{~Hz}, 1 \mathrm{H}), 6.80(\mathrm{~s}, 2 \mathrm{H}), 6.52(\mathrm{~d}, J=8.1$ $\mathrm{Hz}, 2 \mathrm{H}), 5.72(\mathrm{~s}, 1 \mathrm{H}), 4.43(\mathrm{~s}, 1 \mathrm{H}), 4.23(\mathrm{t}, J=7.0 \mathrm{~Hz}, 2 \mathrm{H}), 3.30-3.21$ $(\mathrm{m}, 2 \mathrm{H}), 3.12(\mathrm{~s}, 6 \mathrm{H}), 2.23(\mathrm{~s}, 3 \mathrm{H}), 2.02(\mathrm{~s}, 6 \mathrm{H}), 1.91-1.82(\mathrm{~m}, 2 \mathrm{H})$, 1.79-1.72 (m, 2H). ${ }^{13} \mathrm{C}$ NMR (100 MHz, DMSO- $\left.d_{6}\right) \delta 164.21$, $163.46,157.06,152.56,137.64,136.19,132.92,132.12,131.80$, $131.05,130.15,129.18,128.72,127.22,125.50,124.76,122.67$, 113.79, 113.36, 111.25, 44.94, 42.54, 26.66, 25.92, 20.78, 18.69 . ESI-HRMS: $\mathrm{m} / \mathrm{z}[\mathrm{M}+\mathrm{H}]^{+}$calcd for $\mathrm{C}_{33} \mathrm{H}_{37} \mathrm{~N}_{4} \mathrm{O}_{4} \mathrm{~S}^{+}$585.2536, found 585.2534. HPLC, $t_{R}=8.178 \mathrm{~min}, 97.1 \%$ Purity, mobile phase: methanol-water $(75: 25, v / v), \lambda=254 \mathrm{~nm}$.

4.1.2.9 4-Iodo-N-Mesitylbenzenesulfonamide (4) 2,4,6-trimethylaniline $(232.07 \mu \mathrm{l}, \quad 1.65 \mu \mathrm{mol})$ and pyridine $(399.46 \mu \mathrm{l}, 4.96 \mu \mathrm{mol})$ were added to $10 \mathrm{ml}$ of dry dichloromethane, followed by $p$-iodobenzene sulfonyl chloride (500 mg, $1.65 \mu \mathrm{mol}$ ) dissolved in a small amount of dichloromethane was slowly dropped into the above solution. After stirring at room temperature for $6 \mathrm{~h}$, added $50 \mathrm{ml}$ dichloromethane $(2 \times 20 \mathrm{ml})$ and $1 \mathrm{M}$ hydrochloric acid $(2 \times$ $10 \mathrm{ml}$ ) to the reaction solution for extraction, then combined the organic phases, washed with distilled water twice, and then washed with saturated brine, dried over anhydrous sodium sulfate, filtered, concentrated under reduced pressure. The crude product was purified by silica gel column chromatography with dichloromethane and methanol to afford a white solid. Yield: $520 \mathrm{mg}, 78 \%$, m.p. $178-179^{\circ} \mathrm{C} .{ }^{1} \mathrm{H}$ NMR $\left(400 \mathrm{MHz}, \mathrm{DMSO}-d_{6}\right) \delta 9.34(\mathrm{~s}, 1 \mathrm{H}), 7.97(\mathrm{~d}, J=7.6 \mathrm{~Hz}, 2 \mathrm{H}), 7.41$ (d, $J=7.7 \mathrm{~Hz}, 2 \mathrm{H}), 6.83$ (s, 2H), 2.19 (s, 3H), 1.90 (s, 6H). ESI-MS: $\mathrm{m} / \mathrm{z}[\mathrm{M}-\mathrm{H}]^{-}$calcd for $\mathrm{C}_{15} \mathrm{H}_{15} \mathrm{INO}_{2} \mathrm{~S}^{-} 400.3$, found 400.2 .

\subsubsection{N-(3,4-Dimethoxyphenyl)- \\ 4-Iodobenzenesulfonamide (5)}

From 3,4-dimethoxyaniline $(75.95 \mathrm{mg}, 495.85 \mu \mathrm{mol})$ and 4iodobenzenesulfonyl chloride ( $100 \mathrm{mg}, 330.57 \mu \mathrm{mol})$, according to the synthesis method of intermediate $2(\mathrm{R} 2=2,4,6$-trimethyl), a white solid can be obtained. Yield: $131 \mathrm{mg}, 91 \%, \mathrm{mp}: 142-143^{\circ} \mathrm{C}$. ${ }^{1} \mathrm{H}$ NMR (400 MHz, DMSO- $\left.d_{6}\right) \delta 9.96(\mathrm{~s}, 1 \mathrm{H}), 7.93(\mathrm{~d}, J=8.5 \mathrm{~Hz}$, $2 \mathrm{H}), 7.45(\mathrm{~d}, J=8.5 \mathrm{~Hz}, 2 \mathrm{H}), 6.80(\mathrm{~d}, J=8.6 \mathrm{~Hz}, 1 \mathrm{H}), 6.66(\mathrm{~d}, J=$ $2.4 \mathrm{~Hz}, 1 \mathrm{H}), 6.54(\mathrm{dd}, J=8.6,2.4 \mathrm{~Hz}, 1 \mathrm{H}), 3.65(\mathrm{~d}, J=12.0 \mathrm{~Hz}$, $6 \mathrm{H})$. ESI-MS: $\mathrm{m} / \mathrm{z}[\mathrm{M}-\mathrm{H}]^{-}$calcd for $\mathrm{C}_{14} \mathrm{H}_{13} \mathrm{INO}_{4} \mathrm{~S}^{-}$418.0, found 418.0.

\subsubsection{4-Iodo-N-(3,4,5-Trimethoxyphenyl) benzenesulfonamide (7)}

From 3,4,5-Trimethoxyaniline $(72.67 \mathrm{mg}, 396.68 \mu \mathrm{mol})$ and 4 iodobenzenesulfonyl chloride ( $80 \mathrm{mg}, 264.45 \mu \mathrm{mol})$, according to the synthesis method of intermediate 2 ( $\mathrm{R} 2=2,4,6$-trimethyl), a white solid can be obtained. Yield: $110 \mathrm{mg}, 89.4 \%$, mp: $152-153^{\circ} \mathrm{C}$. ${ }^{1} \mathrm{H}$ NMR (400 MHz, DMSO- $d_{6}$ ) $\delta 10.18(\mathrm{~s}, 1 \mathrm{H}), 7.96$ (d, $J=8.5$ $\mathrm{Hz}, 2 \mathrm{H}), 7.52(\mathrm{~d}, J=8.5 \mathrm{~Hz}, 2 \mathrm{H}), 6.37(\mathrm{~s}, 2 \mathrm{H}), 3.66(\mathrm{~s}, 7 \mathrm{H}), 3.57$ (s, $3 \mathrm{H})$. ESI-MS: $\mathrm{m} / \mathrm{z}[\mathrm{M}-\mathrm{H}]^{-}$calcd for $\mathrm{C}_{15} \mathrm{H}_{15} \mathrm{INO}_{5} \mathrm{~S}^{-}$448.0, found 448.0.

\subsubsection{4-Iodo-N-(4-(trifluoromethoxy)phenyl) benzenesulfonamide (6)}

From 4-trifluoromethoxyaniline $(70.26 \mathrm{mg}, 396.68 \mu \mathrm{mol})$ and 4 iodobenzenesulfonyl chloride ( $80 \mathrm{mg}, 264.45 \mu \mathrm{mol}$ ), according to the synthesis method of intermediate 2 ( $\mathrm{R} 2=2,4,6$-trimethyl), a white solid can be obtained. Yield: $102 \mathrm{mg}, 87 \%$, mp:149-150 ${ }^{\circ} \mathrm{C}$. ${ }^{1} \mathrm{H}$ NMR (400 MHz, DMSO- $\left.d_{6}\right) \delta 10.60(\mathrm{~s}, 1 \mathrm{H}), 7.96$ (d, $J=8.5$ $\mathrm{Hz}, 2 \mathrm{H}), 7.51(\mathrm{~d}, J=8.5 \mathrm{~Hz}, 2 \mathrm{H}), 7.28(\mathrm{~d}, J=8.6 \mathrm{~Hz}, 2 \mathrm{H}), 7.17$ (d, $J=9.0 \mathrm{~Hz}, 2 \mathrm{H})$. ESI-MS: $\mathrm{m} / \mathrm{z}[\mathrm{M}-\mathrm{H}]^{-}$calcd for $\mathrm{C}_{13} \mathrm{H}_{9} \mathrm{~F}_{3} \mathrm{INO}_{3} \mathrm{~S}^{-}$ 441.9 , found 442.1 .

\subsubsection{4-Iodo-N-(4-phenoxyphenyl) benzenesulfonamide (8)}

From 4-phenoxyphenyl aniline $(91.84 \mathrm{mg}, 495.85 \mu \mathrm{mol})$ and 4iodobenzenesulfonyl chloride (100 mg, $330.57 \mu \mathrm{mol})$, according to the synthesis method of intermediate 2 ( $\mathrm{R} 2=2,4,6$-trimethyl), a white solid can be obtained. Yield: $137 \mathrm{mg}, 85.9 \%$, mp: $162-163^{\circ} \mathrm{C} .{ }^{1} \mathrm{H}$ NMR (400 MHz, DMSO- $\left.d_{6}\right) \delta 10.23(\mathrm{~s}, 1 \mathrm{H})$, 
$7.95(\mathrm{~d}, J=8.5 \mathrm{~Hz}, 1 \mathrm{H}), 7.47(\mathrm{~d}, J=8.5 \mathrm{~Hz}, 1 \mathrm{H}), 7.37(\mathrm{t}, J=8.0 \mathrm{~Hz}$, $1 \mathrm{H}), 7.15-7.02(\mathrm{~m}, 2 \mathrm{H}), 6.92(\mathrm{dd}, J=8.2,5.6 \mathrm{~Hz}, 3 \mathrm{H})$. ESI-MS: $\mathrm{m} / \mathrm{z}[\mathrm{M}-\mathrm{H}]^{-}$calcd for $\mathrm{C}_{18} \mathrm{H}_{13} \mathrm{INO}_{3} \mathrm{~S}^{-} 450.0$, found 450.3 .

\subsubsection{N-(4-Fluorophenyl)-4-Iodobenzenesulfonamide (9)} From 4-fluoroaniline (176.32 mg, $1.59 \mathrm{mmol}$ ) and 4iodobenzenesulfonyl chloride $(320 \mathrm{mg}, 1.06 \mathrm{mmol})$, according to the synthesis method of intermediate 2 ( $R 2=2,4,6-$ trimethyl), a white solid can be obtained. Yield: $360 \mathrm{mg}$, 90.23\%, mp:146-147 ${ }^{\circ} \mathrm{C} .{ }^{1} \mathrm{H}$ NMR $\left(400 \mathrm{MHz}\right.$, DMSO- $\left.d_{6}\right) \quad \delta$ $10.30(\mathrm{~s}, 1 \mathrm{H}), 7.94(\mathrm{~d}, J=8.5 \mathrm{~Hz}, 2 \mathrm{H}), 7.45(\mathrm{~d}, J=8.5 \mathrm{~Hz}$, $2 \mathrm{H}), 7.20-6.88(\mathrm{~m}, 4 \mathrm{H})$. ESI-MS: $\mathrm{m} / \mathrm{z}[\mathrm{M}-\mathrm{H}]^{-}$calcd for $\mathrm{C}_{12} \mathrm{H}_{8} \mathrm{FINO}_{2} \mathrm{~S}^{-}$375.9, found 376.1.

\subsubsection{4-Iodo-N-(4-methoxyphenyl)benzenesulfonamide}

(10)

From 3-methoxyaniline $(61.07 \mathrm{mg}, \quad 495.85 \mu \mathrm{mol})$ and 4iodobenzenesulfonyl chloride $(100 \mathrm{mg}, 330.57 \mu \mathrm{mol})$, according to the synthesis method of intermediate $2(\mathrm{R} 2=2,4,6$-trimethyl), a white oil can be obtained. Yield: $106 \mathrm{mg}, 82.3 \% .{ }^{1} \mathrm{H}$ NMR $\left(400 \mathrm{MHz}, \mathrm{DMSO}-d_{6}\right) \delta 10.37(\mathrm{~s}, 1 \mathrm{H}), 7.95(\mathrm{~d}, J=8.5 \mathrm{~Hz}, 2 \mathrm{H})$, $7.52(\mathrm{~d}, J=8.5 \mathrm{~Hz}, 2 \mathrm{H}), 7.14(\mathrm{t}, J=8.4 \mathrm{~Hz}, 1 \mathrm{H}), 6.72-6.57(\mathrm{~m}, 4 \mathrm{H})$. ESI-MS: $\mathrm{m} / \mathrm{z} \quad[\mathrm{M}-\mathrm{H}]^{-}$calcd for $\mathrm{C}_{13} \mathrm{H}_{11} \mathrm{INO}_{3} \mathrm{~S}^{-}$388.0, found 388.4 .

\subsubsection{N-(3,5-Dichlorophenyl)-4-iodobenzenesulfonamide} (11)

From 3,5-Dichloroaniline $(160.67 \mathrm{mg}, 991.7 \mu \mathrm{mol})$ and 4 iodobenzenesulfonyl chloride (200 mg, $661.13 \mu \mathrm{mol})$, according to the synthesis method of intermediate 2 ( $\mathrm{R} 2=2,4,6$-trimethyl), a white solid can be obtained. Yield: $246 \mathrm{mg}, 83.8 \%$, mp: $158-159^{\circ} \mathrm{C}$. ${ }^{1} \mathrm{H}$ NMR $\left(400 \mathrm{MHz}, \mathrm{DMSO}-d_{6}\right) \delta 10.26(\mathrm{~s}, 1 \mathrm{H})$, $7.96(\mathrm{~d}, J=8.5 \mathrm{~Hz}, 2 \mathrm{H}), 7.61(\mathrm{~d}, J=2.4 \mathrm{~Hz}, 1 \mathrm{H}), 7.47-7.37$ $(\mathrm{m}, 3 \mathrm{H}), 7.26(\mathrm{~d}, J=8.7 \mathrm{~Hz}, 1 \mathrm{H})$. ESI-MS: $\mathrm{m} / \mathrm{z}[\mathrm{M}-\mathrm{H}]^{-}$calcd for $\mathrm{C}_{12} \mathrm{H}_{7} \mathrm{Cl}_{2} \mathrm{INO}_{2} \mathrm{~S}^{-}$425.9, found 426.0.

\subsubsection{N-Mesityl-[1,1'-biphenyl]-4-sulfonamide (B1)}

Intermediate $2(200 \mathrm{mg}, 479.27 \mu \mathrm{mol})$, potassium carbonate (198.71 mg, $1.44 \mathrm{mmol}),\left[1,1^{\prime}\right.$-bis(diphenylphosphino) dicene Iron] palladium dichloride $(35.07 \mathrm{mg}, 47.93 \mu \mathrm{mol})$ and phenylboronic acid $(58.44 \mathrm{mg}, 479.27 \mu \mathrm{mol})$ were added to the mixed liquor of $1.6 \mathrm{ml}$ of distilled water and $8 \mathrm{ml}$ of absolute ethanol, pumped off nitrogen three times, heated to $80^{\circ} \mathrm{C}$ under the nitrogen protection for $1 \mathrm{~h}$. After the solution was cooled to room temperature, concentrated most of the solution under reduced pressure at $40^{\circ} \mathrm{C}$. The crude product was purified by silica gel column chromatography with Petroleum ether and ethyl acetate to afford white solids. Yield: $150 \mathrm{mg}, 85.2 \%$, mp: $165-166^{\circ} \mathrm{C}$. ${ }^{1} \mathrm{H}$ NMR $\left(400 \mathrm{MHz}, \mathrm{DMSO}-d_{6}\right) \delta 9.28(\mathrm{~s}, 1 \mathrm{H})$, $7.89(\mathrm{~d}, J=8.4 \mathrm{~Hz}, 2 \mathrm{H}), 7.74(\mathrm{t}, J=7.9 \mathrm{~Hz}, 4 \mathrm{H}), 7.52(\mathrm{t}, J=$ $7.5 \mathrm{~Hz}, 2 \mathrm{H}), 7.44(\mathrm{t}, J=7.3 \mathrm{~Hz}, 1 \mathrm{H}), 6.82(\mathrm{~s}, 2 \mathrm{H}), 2.19(\mathrm{~s}, 3 \mathrm{H}), 1.93$ $(\mathrm{s}, 6 \mathrm{H}) .{ }^{13} \mathrm{C}$ NMR (100 MHZ, DMSO- $\left.d_{6}\right) \delta 144.33,141.22$, $138.82,137.84,136.82,131.13,129.62,129.49,129.02,127.72$, 127.59, 127.48, 20.76, 18.52. ESI-HRMS: $\mathrm{m} / \mathrm{z}[\mathrm{M}+\mathrm{H}]^{+}$calcd for $\mathrm{C}_{21} \mathrm{H}_{22} \mathrm{NO}_{2} \mathrm{~S}^{+}$352.1371, found 352.1378. HPLC, $\mathrm{t}_{\mathrm{R}}=8.896 \mathrm{~min}$, 99.8\% Purity, mobile phase: acetonitrile-water $(75: 25, v / v), \lambda=$ $254 \mathrm{~nm}$.

\subsubsection{8}

4'-Fluoro-N-Mesityl-[1,1'-Biphenyl]-4-Sulfonamide (B2)

From intermediate $2(150 \mathrm{mg}, \quad 359.45 \mu \mathrm{mol})$ and 4fluorophenylboronic acid (50.29 mg, $359.45 \mu \mathrm{mol})$, according to the synthesis method of $\mathrm{B} 1$, a white solid can be obtained. Yield: $112 \mathrm{mg}, 80.8 \%$, mp: $214-215^{\circ} \mathrm{C} .{ }^{1} \mathrm{H}$ NMR $(400 \mathrm{MHz}$, DMSO-d6) $\delta 9.29(\mathrm{~s}, 1 \mathrm{H}), 7.90(\mathrm{~d}, J=8.5 \mathrm{~Hz}, 2 \mathrm{H}), 7.79(\mathrm{~d}$, $J=8.6 \mathrm{~Hz}, 2 \mathrm{H}), 7.73(\mathrm{~d}, J=8.4 \mathrm{~Hz}, 2 \mathrm{H}), 7.57(\mathrm{~d}, J=8.5 \mathrm{~Hz}$, $2 \mathrm{H}), \quad 6.82(\mathrm{~s}, 2 \mathrm{H}), 2.19(\mathrm{~s}, 3 \mathrm{H}), 1.92(\mathrm{~s}, 5 \mathrm{H}) .{ }^{13} \mathrm{C} \mathrm{NMR}$ $(100 \mathrm{MHz}, \quad \mathrm{DMSO}-\mathrm{d} 6) \quad \delta$ 142.95, 141.54, 137.82, 137.62, $136.84,133.96,131.08,129.58,129.49,129.29,127.74$, 127.64, 20.77, 18.72. ESI-HRMS: $\mathrm{m} / \mathrm{z} \quad[\mathrm{M}+\mathrm{K}]^{+}$calcd for $\mathrm{C}_{21} \mathrm{H}_{20} \mathrm{FNO}_{2} \mathrm{SK}^{+}$408.0836, found 408.0838. HPLC, $t_{\mathrm{R}}=$ $10.863 \mathrm{~min}, 99.0 \%$ Purity, mobile phase: acetonitrile-water $(75: 25, v / v), \lambda=254 \mathrm{~nm}$.

\subsubsection{4'-Bromo-N-Mesityl-[1,1'-Biphenyl]-4-Sulfonamide} (B3)

From intermediate $2(150 \mathrm{mg}, \quad 359.45 \mu \mathrm{mol})$ and 4 bromophenylboronic acid (72.19 mg, $359.45 \mu \mathrm{mol})$, according to the synthesis method of $\mathrm{B} 1$, a white solid can be obtained. Yield: $145 \mathrm{mg}, 90.4 \%$, mp: $176-177^{\circ} \mathrm{C} .{ }^{1} \mathrm{H}$ NMR $(400 \mathrm{MHz}$, DMSO-d $d_{6} \delta 9.29(\mathrm{~s}, 1 \mathrm{H}), 7.89(\mathrm{~d}, J=8.5 \mathrm{~Hz}, 2 \mathrm{H}), 7.78-7.66$ $(\mathrm{m}, 6 \mathrm{H}), 6.82$ (s, 2H), 2.19 (s, 3H), 1.93 (s, 6H). ${ }^{13} \mathrm{C}$ NMR (100 MHZ, DMSO- $\left.d_{6}\right) \delta 142.96,141.55,138.01,137.80,136.81$, $132.51,131.09,129.58,129.49,127.69,122.61,20.78,18.51$. ESI-HRMS: $\mathrm{m} / \mathrm{z}[\mathrm{M}+\mathrm{H}]^{+}$calcd for $\mathrm{C}_{21} \mathrm{H}_{21} \mathrm{BrNO}_{2} \mathrm{~S}^{+} 430.0476$, found 430.0468. HPLC, $\mathrm{t}_{\mathrm{R}}=15.161 \mathrm{~min}, 95.3 \%$ Purity, mobile phase: acetonitrile-water $(70: 30, v / v), \lambda=300 \mathrm{~nm}$.

\subsubsection{N-Mesityl-4'-Methyl-[1,1'-Biphenyl]-4-Sulfonamide} (B4)

From intermediate $2(150 \mathrm{mg}, \quad 359.45 \mu \mathrm{mol})$ and 4methylphenylboronic acid (48.87 mg, $359.45 \mu \mathrm{mol})$, according to the synthesis method of B1, a white solid can be obtained. Yield: $117 \mathrm{mg}, 85.3 \%$, mp:195-196 ${ }^{\circ} \mathrm{C} .{ }^{1} \mathrm{H}$ NMR $(400 \mathrm{MHz}$, DMSO- $\left.d_{6}\right) \delta 9.25(\mathrm{~s}, 1 \mathrm{H}), 7.86(\mathrm{~d}, J=8.5 \mathrm{~Hz}, 1 \mathrm{H}), 7.68(\mathrm{dd}$, $J=18.8,8.3 \mathrm{~Hz}, 2 \mathrm{H}), 7.32(\mathrm{~d}, J=8.0 \mathrm{~Hz}, 1 \mathrm{H}), 6.82(\mathrm{~s}, 1 \mathrm{H}), 2.37$ (s, $1 \mathrm{H}), 2.19$ (s, 2H), $1.93(\mathrm{~s}, 3 \mathrm{H}) .{ }^{13} \mathrm{C}$ NMR (100 MHZ, DMSO- $\left.d_{6}\right) \delta$ $144.23,140.87,138.56,137.83,136.79,135.90,131.14,130.20$, 129.48, 127.57, 127.36, 127.29, 21.18, 20.88, 18.82. ESI-HRMS: $\mathrm{m} / \mathrm{z}[\mathrm{M}+\mathrm{H}]^{+}$calcd for $\mathrm{C}_{22} \mathrm{H}_{24} \mathrm{NO}_{2} \mathrm{~S}^{+} 366.1528$, found 366.1449 . HPLC, $\mathrm{t}_{\mathrm{R}}=10.444 \mathrm{~min}, 99.3 \%$ Purity, mobile phase: acetonitrilewater $(75: 25, v / v), \lambda=254 \mathrm{~nm}$.

\subsubsection{N-Mesityl-4' -(Trifluoromethoxy)-[1,1'-Biphenyl]- 4-Sulfonamide (B5)}

From intermediate $2(60 \mathrm{mg}, 143.78 \mu \mathrm{mol})$ and 4 trifluoromethoxyphenylboronic acid $(29.61 \mathrm{mg}, 143.78 \mu \mathrm{mol})$, according to the synthesis method of $\mathrm{B} 1$, a white solid can be obtained. Yield: $57 \mathrm{mg}, \quad 87.8 \%, \mathrm{mp}: 169-170^{\circ} \mathrm{C} .{ }^{1} \mathrm{H} \quad \mathrm{NMR}$ $\left(400 \mathrm{MHz}, \mathrm{DMSO}-d_{6}\right) \delta 9.30(\mathrm{~s}, 1 \mathrm{H}), 7.90(\mathrm{t}, J=8.0 \mathrm{~Hz}, 4 \mathrm{H})$, $7.74(\mathrm{~d}, J=8.3 \mathrm{~Hz}, 2 \mathrm{H}), 7.51(\mathrm{~d}, J=8.4 \mathrm{~Hz}, 2 \mathrm{H}), 6.82(\mathrm{~s}, 2 \mathrm{H}), 2.19$ $(\mathrm{s}, 3 \mathrm{H}), 1.93(\mathrm{~s}, 6 \mathrm{H}) .{ }^{13} \mathrm{C}$ NMR $\left(100 \mathrm{MHz}, \mathrm{DMSO}-d_{6}\right) \delta 149.03(\mathrm{~s})$, 142.83 (s), 141.65 (s), 138.13 (s), 137.83 (s), 136.84 (s), 131.04 (s), 129.53 (s), 129.49 (s), 127.95 (s), 127.63 (s), 122.07 (s), 120.52 (q, $J=284.0 \mathrm{~Hz}$ ), 20.87 (s), 18.80 (s). ESI-HRMS: m/z $[\mathrm{M}+\mathrm{H}]^{+}$calcd 
for $\mathrm{C}_{22} \mathrm{H}_{21} \mathrm{~F}_{3} \mathrm{NO}_{3} \mathrm{~S}^{+}$436.1194, found 436.1184. HPLC, $t_{\mathrm{R}}=$ $12.019 \mathrm{~min}, 99.1 \%$ Purity, mobile phase: acetonitrile-water (75: $25, v / v), \lambda=254 \mathrm{~nm}$.

\subsubsection{4'-Amino-3'-Fluoro-N-Mesityl-[1,1'-Biphenyl]-4- Sulfonamide (B6)}

From intermediate $2(100 \mathrm{mg}, 239.63 \mu \mathrm{mol})$ and 4 -amino-3fluorophenylboronic acid (37.13 mg, $239.63 \mu \mathrm{mol})$, according to the synthesis method of B1, a white solid can be obtained. Yield: $70 \mathrm{mg}, 72.9 \%$, mp:176-177 ${ }^{\circ} \mathrm{C} .{ }^{1} \mathrm{H}$ NMR (400 MHz, DMSO$\left.d_{6}\right) \delta 9.18(\mathrm{~s}, 1 \mathrm{H}), 7.79(\mathrm{~d}, J=8.5 \mathrm{~Hz}, 2 \mathrm{H}), 7.62(\mathrm{~d}, J=8.5 \mathrm{~Hz}, 2 \mathrm{H})$, $7.48(\mathrm{dd}, J=13.1,1.9 \mathrm{~Hz}, 1 \mathrm{H}), 7.36(\mathrm{dd}, J=8.3,1.9 \mathrm{~Hz}, 1 \mathrm{H})$, 6.93-6.73 (m, 3H), 5.49 (s, 2H), 2.19 (s, 3H), $1.92(\mathrm{~s}, 6 \mathrm{H}) .{ }^{13} \mathrm{C}$ NMR (100 MHz, DMSO- $\left.d_{6}\right) \delta 151.25(\mathrm{~d}, J=237.1 \mathrm{~Hz}), 143.56(\mathrm{~s})$, 139.78 (s), 137.84 (s), 137.65 (d, $J=13.0 \mathrm{~Hz}), 136.74$ (s), 131.20 (s), 129.46 (s), 127.50 (s), 126.15 (s), 126.08 (d, J=6.5 Hz), 123.62 $(\mathrm{d}, J=2.3 \mathrm{~Hz}), 116.81(\mathrm{~d}, \mathrm{~J}=5.2 \mathrm{~Hz}), 113.74(\mathrm{~d}, \mathrm{~J}=19.3 \mathrm{~Hz}), 20.88$ (s), 18.83 (s). ESI-HRMS: m/z $[\mathrm{M}+\mathrm{H}]^{+}$calcd for $\mathrm{C}_{21} \mathrm{H}_{22} \mathrm{FN}_{2} \mathrm{O}_{2} \mathrm{~S}^{+}$ 385.1386, found 385.1371. HPLC, $t_{R}=5.114$ min, 98.2\% Purity, mobile phase: acetonitrile-water $(75: 25, v / v), \lambda=300 \mathrm{~nm}$.

\subsubsection{N-Mesityl-4-(Naphthalen-2-yl)benzenesulfonamide} (B7)

From intermediate $2(60 \mathrm{mg}, \quad 143.78 \mu \mathrm{mol})$ and 2 naphthylbenzeneboronic acid $(24.73 \mathrm{mg}, 143.78 \mu \mathrm{mol})$, according to the synthesis method of $\mathrm{B} 1$, a white solid can be obtained. Yield: $48 \mathrm{mg}, 80 \%$, mp:211-212 ${ }^{\circ} \mathrm{C}$. ${ }^{1} \mathrm{H}$ NMR $(400 \mathrm{MHz}$, DMSO- $\left.d_{6}\right) \delta 9.31(\mathrm{~s}, 1 \mathrm{H}), 8.36(\mathrm{~s}, 1 \mathrm{H}), 8.05(\mathrm{dd}, J=8.3,6.9 \mathrm{~Hz}$, $4 \mathrm{H}), 8.00-7.95(\mathrm{~m}, 1 \mathrm{H}), 7.92(\mathrm{dd}, J=8.6,1.7 \mathrm{~Hz}, 1 \mathrm{H}), 7.78(\mathrm{~d}, J=$ $8.4 \mathrm{~Hz}, 2 \mathrm{H}), 7.58$ (dt, $J=5.4,3.3 \mathrm{~Hz}, 2 \mathrm{H}), 6.83$ (s, 2H), 2.19 (s, $3 \mathrm{H}), 1.95(\mathrm{~s}, 6 \mathrm{H}) .{ }^{13} \mathrm{C}$ NMR (100 MHZ, DMSO- $\left.d_{6}\right) \delta 144.17$, $141.27,137.85,136.83,136.12,133.67,133.15,131.14,129.51$, $129.22,128.89,128.00,127.66,127.19,127.14,126.61,125.33$, 20.89, 18.85. ESI-HRMS: $\mathrm{m} / \mathrm{z}[\mathrm{M}+\mathrm{H}]^{+}$calcd for $\mathrm{C}_{25} \mathrm{H}_{24} \mathrm{NO}_{2} \mathrm{~S}^{+}$ 402.1528, found 402.1519. HPLC, $\mathrm{t}_{\mathrm{R}}=11.465 \mathrm{~min}, 99.8 \%$ Purity, mobile phase: acetonitrile-water $(75: 25, v / v), \lambda=254 \mathrm{~nm}$.

\subsubsection{4'-Chloro-N-Mesityl-[1,1'-Biphenyl]-4-Sulfonamide (B8)}

From intermediate $2(150 \mathrm{mg}, \quad 359.45 \mu \mathrm{mol})$ and 4chlorophenylboronic acid (56.21 mg, $359.45 \mu \mathrm{mol})$, according to the synthesis method of $\mathrm{B} 1$, a white solid can be obtained. Yield: $121 \mathrm{mg}, 83.8 \%$, mp:214-215 ${ }^{\circ} \mathrm{C} .{ }^{1} \mathrm{H}$ NMR $(400 \mathrm{MHz}$, DMSO- $\left.d_{6}\right) \delta 9.30(\mathrm{~s}, 1 \mathrm{H}), 7.89(\mathrm{~d}, J=8.4 \mathrm{~Hz}, 2 \mathrm{H}), 7.79(\mathrm{~d}, J=$ $8.6 \mathrm{~Hz}, 2 \mathrm{H}), 7.73(\mathrm{~d}, J=8.5 \mathrm{~Hz}, 2 \mathrm{H}), 7.57(\mathrm{~d}, J=8.6 \mathrm{~Hz}, 2 \mathrm{H}), 6.82$ (s, 2H), 2.18 (s, 3H), 1.92 (s, 6H). ${ }^{13} \mathrm{C}$ NMR (100 MHZ, DMSO$\left.d_{6}\right) \delta 142.96,141.53,137.83,137.62,136.85,133.96,131.07$, $129.58,129.49,129.29,127.73,127.64,20.77,18.75$. ESIHRMS: $\mathrm{m} / \mathrm{z} \quad[\mathrm{M}+\mathrm{H}]^{+}$calcd for $\mathrm{C}_{21} \mathrm{H}_{21} \mathrm{ClNO}_{2} \mathrm{~S}^{+}$386.0982, found 386.0983. HPLC, $t_{R}=10.809 \mathrm{~min}, 99.3 \%$ Purity, mobile phase: acetonitrile-water $(75: 25, v / v), \lambda=254 \mathrm{~nm}$.

\subsubsection{N-(3,4-Dimethoxyphenyl)-4' -(Trifluoromethoxy)- [1,1'-Biphenyl]-4-Sulfonamide (D1)}

From intermediate $2 \quad(100 \mathrm{mg}, \quad 229.74 \mu \mathrm{mol}), \quad 4-$ trifluoromethoxyphenylboronic acid $(47.31 \mathrm{mg}, 229.74 \mu \mathrm{mol})$, according to the synthesis method of B1, a white solid can be obtained. Yield: $87 \mathrm{mg}, \quad 80.7 \%, \quad \mathrm{mp}: 145-146^{\circ} \mathrm{C} .{ }^{1} \mathrm{H} \quad \mathrm{NMR}$ $\left(400 \mathrm{MHz}, \mathrm{DMSO}-d_{6}\right) \delta 9.99(\mathrm{~s}, 1 \mathrm{H}), 7.94-7.74(\mathrm{~m}, 7 \mathrm{H}), 7.48$ $(\mathrm{d}, J=8.4 \mathrm{~Hz}, 3 \mathrm{H}), 6.81(\mathrm{~d}, J=8.6 \mathrm{~Hz}, 1 \mathrm{H}), 6.71(\mathrm{~d}, J=2.3 \mathrm{~Hz}$, $1 \mathrm{H}), 6.61(\mathrm{~d}, J=2.3 \mathrm{~Hz}, 1 \mathrm{H}), 3.65(\mathrm{~d}, J=9.6 \mathrm{~Hz}, 8 \mathrm{H}) .{ }^{13} \mathrm{C} \mathrm{NMR}$ $\left(100 \mathrm{MHz}, \mathrm{DMSO}-d_{6}\right) \delta 149.26(\mathrm{~s}), 149.04(\mathrm{~s}), 146.63$ (s), 143.11 (s), 139.20 (s), 138.10 (s), 130.90 (s), 129.56 (s), 127.96 (s), 122.01 (s), 120.48 (q, $J=256.0 \mathrm{~Hz}), 114.03$ (s), 112.57 (s), 106.95 (s), 56.04 (s), 55.86 (s). ESI-HRMS: $\mathrm{m} / \mathrm{z} \quad[\mathrm{M}+\mathrm{H}]^{+}$calcd for $\mathrm{C}_{21} \mathrm{H}_{19} \mathrm{~F}_{3} \mathrm{NO}_{5} \mathrm{~S}^{+}$454.0936, found 454.0939. HPLC, $t_{\mathrm{R}}=$ $5.229 \mathrm{~min}, 95.3 \%$ Purity, mobile phase: acetonitrile-water (75: $25, v / v), \lambda=254 \mathrm{~nm}$.

\subsubsection{4'-(Trifluoromethoxy)-N-(4-(Trifluoromethoxy) phenyl)-[1,1'-Biphenyl]-4-Sulfonamide (D2)}

From intermediate $2 \quad(100 \mathrm{mg}, \quad 217.76 \mu \mathrm{mol}), \quad 4$ trifluoromethoxyphenylboronic acid $(44.84 \mathrm{mg}, 217.76 \mu \mathrm{mol})$, according to the synthesis method of B1, a white solid can be obtained. Yield: $94 \mathrm{mg}, \quad 87.5 \%, \quad \mathrm{mp}: 139-140^{\circ} \mathrm{C} .{ }^{1} \mathrm{H} \quad \mathrm{NMR}$ $\left(400 \mathrm{MHz}, \mathrm{DMSO}-d_{6}\right) \delta 10.64(\mathrm{~s}, 1 \mathrm{H}), 7.93-7.81(\mathrm{~m}, 1 \mathrm{H}), 7.48$ $(\mathrm{d}, J=8.1 \mathrm{~Hz}, 1 \mathrm{H}), 7.31-7.20(\mathrm{~m}, 1 \mathrm{H}) .{ }^{13} \mathrm{C} \mathrm{NMR}(100 \mathrm{MHz}$, DMSO-d $\left.d_{6}\right) 149.10$ (s), 144.91 (s), 143.47 (s), 138.97 (s), 137.93 (s), 137.33 (s), 129.62 (s), 128.22 (s), 127.82 (s), 122.63 (s), 122.01 (s), 121.69 (s), 120.57 (q, $J=256.0 \mathrm{~Hz}), 120.47(\mathrm{q}, J=256.0 \mathrm{~Hz})$. ESI-HRMS: $\mathrm{m} / \mathrm{z}[\mathrm{M}+\mathrm{H}]^{+}$calcd for $\mathrm{C}_{20} \mathrm{H}_{14} \mathrm{~F}_{6} \mathrm{NO}_{4} \mathrm{~S}^{+}$478.0548, found 478.0555 . HPLC, $\mathrm{t}_{\mathrm{R}}=5.427 \mathrm{~min}, 98.9 \%$ Purity, mobile phase: acetonitrile-water $(75: 25, v / v), \lambda=254 \mathrm{~nm}$.

\subsubsection{4'-(Trifluoromethoxy)-N-(3,4,5-Trimethoxyphenyl)- [1,1'-Biphenyl]-4-Sulfonamide (D3)}

From intermediate $2 \quad(44.84 \mathrm{mg}, \quad 217.76 \mu \mathrm{mol}), \quad 4$ trifluoromethoxyphenylboronic acid (44.84 mg, $217.76 \mu \mathrm{mol})$, according to the synthesis method of B1, a white solid can be obtained. Yield: $94 \mathrm{mg}, 84.6 \%, \mathrm{mp}: 136-137^{\circ} \mathrm{C} .{ }^{1} \mathrm{H} \quad \mathrm{NMR}$ $\left(400 \mathrm{MHz}, \mathrm{DMSO}-d_{6}\right) \delta 10.19(\mathrm{~s}, 1 \mathrm{H}), 7.86(\mathrm{~d}, J=19.9 \mathrm{~Hz}$, $6 \mathrm{H}), 7.48(\mathrm{~d}, J=8.3 \mathrm{~Hz}, 2 \mathrm{H}), 6.43(\mathrm{~s}, 2 \mathrm{H}), 3.66(\mathrm{~s}, 6 \mathrm{H}), 3.56$ $(\mathrm{s}, 3 \mathrm{H}) .{ }^{13} \mathrm{C}$ NMR $\left(100 \mathrm{MHz}, \mathrm{DMSO}-d_{6}\right) \delta 153.48(\mathrm{~s}), 149.06(\mathrm{~s})$, 143.31 (s), 139.16 (s), 138.09 (s), 134.78 (s), 133.99 (s), 129.59 (s), 128.08 (s), 128.02 (s), 122.01 (s), 120.55 (q, J=256.0 Hz), 98.57 (s), 60.51 (s), 56.23 (s) ESI-HRMS: $\mathrm{m} / \mathrm{z}[\mathrm{M}+\mathrm{H}]^{+}$calcd for $\mathrm{C}_{22} \mathrm{H}_{21} \mathrm{~F}_{3} \mathrm{NO}_{6} \mathrm{~S}^{+}$484.1042, found 484.1050. HPLC, $t_{\mathrm{R}}=$ $9.042 \mathrm{~min}, 99.7 \%$ Purity, mobile phase: acetonitrile-water (75: $25, v / v), \lambda=254 \mathrm{~nm}$.

\subsubsection{N-(4-Phenoxyphenyl)-4' -(Trifluoromethoxy)- [1,1'-Biphenyl]-4-Sulfonamide (D4)}

From intermediate 2 (75 mg, $160.49 \mu \mathrm{mol}), \quad 4-$ trifluoromethoxyphenylboronic acid (33.05 mg, $160.49 \mu \mathrm{mol}$ ), according to the synthesis method of B1, a white solid can be obtained. Yield: $68 \mathrm{mg}, \quad 84.5 \%, \mathrm{mp}: 144-145^{\circ} \mathrm{C} .{ }^{1} \mathrm{H} \quad \mathrm{NMR}$ $\left(400 \mathrm{MHz}, \mathrm{DMSO}-d_{6}\right) \delta 10.28(\mathrm{~s}, 1 \mathrm{H}), 7.92-7.79(\mathrm{~m}, 6 \mathrm{H}), 7.49$ $(\mathrm{d}, J=8.2 \mathrm{~Hz}, 2 \mathrm{H}), 7.35(\mathrm{dd}, J=10.7,5.2 \mathrm{~Hz}, 2 \mathrm{H}), 7.12(\mathrm{t}, J=$ $8.2 \mathrm{~Hz}, 3 \mathrm{H}), 6.92(\mathrm{~d}, J=8.8 \mathrm{~Hz}, 4 \mathrm{H}) .{ }^{13} \mathrm{C} \mathrm{NMR}(100 \mathrm{MHz}$, DMSO- $\left.d_{6}\right) \delta 157.27(\mathrm{~s}), 153.68(\mathrm{~s}), 149.05(\mathrm{~s}), 143.22(\mathrm{~s})$, 139.16 (s), 138.04 (s), 133.50 (s), 130.47 (s), 129.59 (s), 128.06 (s), 127.87 (s), 123.77 (s), 123.18 (s), 122.03 (s), 120.58 (q, $J=$ $250.1 \mathrm{~Hz}$ ), 120.05 (s), 118.67 (s). ESI-HRMS: m/z [M+H] ${ }^{+} \mathrm{calcd}$ for $\mathrm{C}_{25} \mathrm{H}_{19} \mathrm{~F}_{3} \mathrm{NO}_{4} \mathrm{~S}^{+}$486.0987, found 486.0989. HPLC, $t_{R}=$ 
9.259 min, $97.8 \%$ Purity, mobile phase: acetonitrile-water (75:25, $v / v), \lambda=280 \mathrm{~nm}$.

\subsubsection{N-(4-Fluorophenyl)-4'-(Trifluoromethoxy)- [1,1'-Biphenyl]-4-Sulfonamide (D5)}

From intermediate $2 \quad(300 \mathrm{mg}, \quad 762.94 \mu \mathrm{mol}), \quad 4$ trifluoromethoxyphenylboronic acid $(157.11 \mathrm{mg}, 762.94 \mu \mathrm{mol})$, according to the synthesis method of $\mathrm{B} 1$, a white solid can be obtained. Yield: $267 \mathrm{mg}, 81.9 \%$, mp:148-149 ${ }^{\circ} \mathrm{C} .{ }^{1} \mathrm{H}$ NMR $\left(400 \mathrm{MHz}, \mathrm{DMSO}-d_{6}\right) \delta 10.32(\mathrm{~s}, 1 \mathrm{H}), 7.91-7.77(\mathrm{~m}, 8 \mathrm{H}), 7.48$ $(\mathrm{d}, J=8.2 \mathrm{~Hz}, 3 \mathrm{H}), 7.18-7.07(\mathrm{~m}, 5 \mathrm{H}) .{ }^{13} \mathrm{C}$ NMR $(100 \mathrm{MHz}$, DMSO- $\left.d_{6}\right) \delta 159.58(\mathrm{~d}, J=241.2 \mathrm{~Hz}), 149.07(\mathrm{~s}), 143.29(\mathrm{~s})$, $138.94(\mathrm{~s}), 137.99(\mathrm{~s}), 134.27(\mathrm{~d}, J=2.6 \mathrm{~Hz}), 129.58(\mathrm{~s}), 128.08(\mathrm{~s})$, $127.86(\mathrm{~s}), 123.26(\mathrm{~d}, J=8.3 \mathrm{~Hz}), 122.00(\mathrm{~s}), 120.54(\mathrm{q}, J=$ $256.7 \mathrm{~Hz}), 116.42(\mathrm{~d}, J=22.6 \mathrm{~Hz})$. ESI-HRMS: $\mathrm{m} / \mathrm{z}[\mathrm{M}+\mathrm{H}]^{+}$calcd for $\mathrm{C}_{19} \mathrm{H}_{14} \mathrm{~F}_{4} \mathrm{NO}_{3} \mathrm{~S}^{+}$412.0631, found 412.0643. HPLC, $\mathrm{t}_{\mathrm{R}}=6.639$ $\min , 99.3 \%$ Purity, mobile phase: acetonitrile-water $(75: 25, v / v), \lambda$ $=254 \mathrm{~nm}$.

\subsubsection{N-(4-Methoxyphenyl)-4' -(Trifluoromethoxy)- [1,1'-Biphenyl]-4-Sulfonamide (D6)}

From intermediate $2 \quad(105 \mathrm{mg}, \quad 259.1 \mu \mathrm{mol}), \quad 4-$ trifluoromethoxyphenylboronic acid $(53.36 \mathrm{mg}, 259.1 \mu \mathrm{mol})$, according to the synthesis method of $\mathrm{B} 1$, a white oil can be obtained. Yield: $102 \mathrm{mg}, 90 \% .{ }^{1} \mathrm{H}$ NMR $\left(400 \mathrm{MHz}, \mathrm{DMSO}-d_{6}\right) \delta$ $10.41(\mathrm{~s}, 1 \mathrm{H}), 7.91-7.79(\mathrm{~m}, 6 \mathrm{H}), 7.47(\mathrm{~d}, J=8.2 \mathrm{~Hz}, 2 \mathrm{H}), 7.14(\mathrm{t}$, $J=8.3 \mathrm{~Hz}, 1 \mathrm{H}), 6.77-6.70(\mathrm{~m}, 2 \mathrm{H}), 6.64-6.58(\mathrm{~m}, 1 \mathrm{H}), 3.66(\mathrm{~s}$, $3 \mathrm{H}) .{ }^{13} \mathrm{C}$ NMR $\left(100 \mathrm{MHz}, \mathrm{DMSO}-d_{6}\right) \delta 160.16(\mathrm{~s}), 149.05(\mathrm{~s})$, $143.30(\mathrm{~s}), 139.35(\mathrm{~s}), 139.16(\mathrm{~s}), 138.03(\mathrm{~s}), 130.57(\mathrm{~s}), 129.58(\mathrm{~s})$, $128.12(\mathrm{~s}), 127.88(\mathrm{~s}), 121.99(\mathrm{~s}), 120.54(\mathrm{q}, J=256.5 \mathrm{~Hz}), 112.28$ (s), $109.52(\mathrm{~s}), 106.10(\mathrm{~s}), 55.32(\mathrm{~s})$. ESI-HRMS: $\mathrm{m} / \mathrm{z}[\mathrm{M}+\mathrm{H}]^{+}$ calcd for $\mathrm{C}_{20} \mathrm{H}_{17} \mathrm{~F}_{3} \mathrm{NO}_{4} \mathrm{~S}^{+} 424.0830$, found 424.0840 . HPLC, $\mathrm{t}_{\mathrm{R}}=$ $6.258 \mathrm{~min}, 99.5 \%$ Purity, mobile phase: acetonitrile-water (75:25, $v / v), \lambda=254 \mathrm{~nm}$.

\subsubsection{N-(2,4-Dichlorophenyl)-4-(naphthalen-2-yl) benzenesulfonamide (D7)}

From intermediate $2 \quad(100 \mathrm{mg}, \quad 233.61 \mu \mathrm{mol}), \quad 4$ trifluoromethoxyphenylboronic acid (40.18 mg, $233.61 \mu \mathrm{mol})$, according to the synthesis method of $\mathrm{B} 1$, a white solid can be obtained. Yield: $81 \mathrm{mg}, 81 \%$, mp: $175-176^{\circ} \mathrm{C} .{ }^{1} \mathrm{H}$ NMR $(400 \mathrm{MHz}$, DMSO- $\left.d_{6}\right) \delta 10.23(\mathrm{~s}, 1 \mathrm{H}), 8.34(\mathrm{~s}, 1 \mathrm{H}), 8.04(\mathrm{dd}, J=8.3,6.5 \mathrm{~Hz}$, $4 \mathrm{H}), 8.00-7.95(\mathrm{~m}, 1 \mathrm{H}), 7.91(\mathrm{~d}, J=1.7 \mathrm{~Hz}, 1 \mathrm{H}), 7.84(\mathrm{~d}, J=$ $8.5 \mathrm{~Hz}, 2 \mathrm{H}), 7.62-7.55(\mathrm{~m}, 3 \mathrm{H}), 7.40(\mathrm{~d}, J=2.4 \mathrm{~Hz}, 1 \mathrm{H}), 7.33$ (d, $J=8.7 \mathrm{~Hz}, 1 \mathrm{H}) .{ }^{13} \mathrm{C}$ NMR $\left(100 \mathrm{MHZ}, \mathrm{DMSO}-d_{6}\right) \delta 144.64$, $139.56,136.02,133.64,133.17,131.36,130.56,129.88,129.21$, $128.89,128.46,128.08,128.02,127.87,127.23,127.15,126.71$, 125.31. ESI-HRMS: $\mathrm{m} / \mathrm{z}[\mathrm{M}+\mathrm{H}]^{+}$calcd for $\mathrm{C}_{22} \mathrm{H}_{16} \mathrm{Cl}_{2} \mathrm{NO}_{2} \mathrm{~S}^{+}$ 428.0279, found 428.0293. HPLC, $t_{R}=9.622 \mathrm{~min}, 97 \%$ Purity, mobile phase: acetonitrile-water $(75: 25, v / v), \lambda=254 \mathrm{~nm}$.

\subsubsection{4-Hydroxy-N-mesitylbenzenesulfonamide (12)}

2,4,6-trimethylaniline $(210.59 \mathrm{mg}, 1.56 \mathrm{mmol})$ and pyridine $(246.41 \mathrm{mg}, \quad 3.12 \mathrm{mmol}$ ) were added to $10 \mathrm{ml}$ of dry dichloromethane, followed by $p$-iodobenzene sulfonyl chloride $(200 \mathrm{mg}, 1.04 \mathrm{mmol})$ dissolved in a small amount of dichloromethane was slowly dropped into the above solution.
After stirring at room temperature for $6 \mathrm{~h}$, added $50 \mathrm{ml}$ dichloromethane $(2 \times 20 \mathrm{ml})$ and $1 \mathrm{M}$ hydrochloric acid $(2 \times$ $10 \mathrm{ml}$ ) to the reaction solution for extraction, then combined the organic phases, washed with distilled water twice, and then washed with saturated brine, dried over anhydrous sodium sulfate, filtered, concentrated under reduced pressure. The crude product was purified by silica gel column chromatography with dichloromethane and methanol to afford a white solid. Yield: $256 \mathrm{mg}, 84.6 \%, \mathrm{mp}: 208-209^{\circ} \mathrm{C} .{ }^{1} \mathrm{H}$ NMR $\left(400 \mathrm{MHz}\right.$, DMSO- $\left.d_{6}\right) \delta 10.38(\mathrm{~s}, 1 \mathrm{H}), 8.92(\mathrm{~s}, 1 \mathrm{H}), 7.45(\mathrm{~d}, J=8.7$ $\mathrm{Hz}, 2 \mathrm{H}), 6.90-6.77$ (m, 5H), 2.18 (s, 3H), 1.91 (s, 6H). ESI-MS: $\mathrm{m} / \mathrm{z}[\mathrm{M}-\mathrm{H}]^{-}$calcd for $\mathrm{C}_{15} \mathrm{H}_{16} \mathrm{NO}_{3} \mathrm{~S}^{-} 290.1$, found 290.2 .

\subsubsection{4-((3,5-Dimethylbenzyl)} oxy)- $\mathrm{N}$-mesitylbenzenesulfonamide (C1)

Intermediate $3(100 \mathrm{mg}, 325.3 \mu \mathrm{mol})$, potassium carbonate (134.87 mg, $975.9 \mu \mathrm{mol}), 3,5$-dimethylbenzyl bromide (97.15 $\mathrm{mg}, 487.95 \mu \mathrm{mol})$ were added to anhydrous acetonitrile, and after stirring for $7 \mathrm{~h}$ at room temperature, the solvent of the reaction solution was evaporated, washed 3 times with water, 3 times with saturated sodium chloride solution, dried with anhydrous sodium sulfate for $2 \mathrm{~h}$, filtered and separated by column chromatography (petroleum ether: ethyl acetate $=5: 1$ ) to obtain a white solid. Yield: $97 \mathrm{mg}, 70.1 \%$, mp: $152-153^{\circ} \mathrm{C} .{ }^{1} \mathrm{H}$ NMR (400 MHz, DMSO- $\left.d_{6}\right) \delta 9.04(\mathrm{~s}, 1 \mathrm{H}), 7.56(\mathrm{~d}, J=8.8 \mathrm{~Hz}$, $2 \mathrm{H}), 7.14(\mathrm{~d}, J=8.9 \mathrm{~Hz}, 2 \mathrm{H}), 7.04(\mathrm{~s}, 2 \mathrm{H}), 6.98(\mathrm{~s}, 1 \mathrm{H}), 6.80(\mathrm{~s}$, $2 \mathrm{H}), 5.11(\mathrm{~s}, 2 \mathrm{H}), 2.28(\mathrm{~s}, 7 \mathrm{H}), 2.18(\mathrm{~s}, 3 \mathrm{H}), 1.90(\mathrm{~s}, 7 \mathrm{H}) .{ }^{13} \mathrm{C} \mathrm{NMR}$ $\left(100 \mathrm{MHZ}, \mathrm{DMSO}-d_{6}\right) \delta 161.79,138.00,137.80,136.66,136.59$, 134.32, 131.27, 129.86, 129.43, 129.02, 125.94, 70.12, 21.27, 20.76, 18.69. ESI-HRMS: $\mathrm{m} / \mathrm{z}[\mathrm{M}+\mathrm{H}]^{+}$calcd for $\mathrm{C}_{24} \mathrm{H}_{28} \mathrm{NO}_{3} \mathrm{~S}^{+}$ 410.1790, found 410.1791. HPLC, $t_{R}=9.676 \mathrm{~min}, 99.5 \%$ Purity, mobile phase: acetonitrile-water $(75: 25, v / v), \lambda=254 \mathrm{~nm}$.

\subsubsection{4-((2-Fluoro-6-(trifluoromethyl)benzyl) oxy)-N-mesitylbenzenesulfonamide (C2)}

From intermediate $3(60 \mathrm{mg}, \quad 195.18 \mu \mathrm{mol}), \quad 2$-Fluoro-6(trifluoromethyl)benzyl bromide $(75.25 \mathrm{mg}, 292.77 \mu \mathrm{mol})$, according to the synthesis method of $\mathrm{C} 1$, a white solid can be obtained. Yield: $78 \mathrm{mg}, \quad 82.7 \%$, mp:154-155 ${ }^{\circ} \mathrm{C} .{ }^{1} \mathrm{H}$ NMR $\left(400 \mathrm{MHz}, \mathrm{DMSO}-d_{6}\right) \delta 9.09(\mathrm{~s}, 1 \mathrm{H}), 7.76-7.68(\mathrm{~m}, 3 \mathrm{H}), 7.59$ $(\mathrm{d}, J=8.8 \mathrm{~Hz}, 2 \mathrm{H}), 7.20(\mathrm{~d}, J=8.9 \mathrm{~Hz}, 2 \mathrm{H}), 6.81(\mathrm{~s}, 2 \mathrm{H}), 5.25(\mathrm{~s}$, $2 \mathrm{H}), 2.19(\mathrm{~s}, 2 \mathrm{H}), 1.91(\mathrm{~s}, 5 \mathrm{H}) .{ }^{13} \mathrm{C}$ NMR $\left(100 \mathrm{MHz}\right.$, DMSO- $\left.d_{6}\right) \delta$ $162.06(\mathrm{~d}, J=248.9 \mathrm{~Hz}), 161.55$ (s), 137.77 (s), 136.69 (s), 134.98 (s), $132.74(\mathrm{~s}), 131.24(\mathrm{~s}), 130.93(\mathrm{~d}, J=9.7 \mathrm{~Hz}), 130.53$ (d, $J=$ $3.8 \mathrm{~Hz}), 129.47(\mathrm{~s}), 129.11(\mathrm{~s}), 125.26(\mathrm{~d}, J=3.2 \mathrm{~Hz}), 123.05(\mathrm{q}, J=$ $3.3 \mathrm{~Hz}), 125.89-118.43(\mathrm{~m}), 120.96(\mathrm{~d}, J=22.7 \mathrm{~Hz})$. ESI-HRMS: $\mathrm{m} / \mathrm{z}[\mathrm{M}+\mathrm{H}]^{+}$calcd for $\mathrm{C}_{23} \mathrm{H}_{22} \mathrm{~F}_{4} \mathrm{NO}_{3} \mathrm{~S}^{+}$468.1257, found 468.1245. HPLC, $t_{R}=9.691$ min, $99.1 \%$ Purity, mobile phase: acetonitrile-water $(75: 25, v / v), \lambda=254 \mathrm{~nm}$.

\subsubsection{4-((4-Bromobenzyl)}

oxy)-N-mesitylbenzenesulfonamide (C3)

From intermediate $3(139.89 \mathrm{mg}, 480.13 \mu \mathrm{mol})$, 4-bromobenzyl bromide $(100 \mathrm{mg}, 400.11 \mu \mathrm{mol})$, according to the synthesis method of C1, a white solid can be obtained. Yield: $147 \mathrm{mg}$, $79.8 \%$, mp:161-162 ${ }^{\circ} \mathrm{C} .{ }^{1} \mathrm{H}$ NMR $\left(400 \mathrm{MHz}\right.$, DMSO- $\left.d_{6}\right) \delta 9.06$ (s, $1 \mathrm{H}), 7.58(\mathrm{dd}, J=20.7,8.6 \mathrm{~Hz}, 4 \mathrm{H}), 7.43(\mathrm{~d}, 2 \mathrm{H}), 6.79(\mathrm{~s}, 2 \mathrm{H}), 5.19$ 
(s, 2H), 2.18 (s, 3H), 1.88 (s, 6H). ${ }^{13} \mathrm{C}$ NMR (100 MHZ, DMSO$\left.d_{6}\right) \delta 161.60,137.89,136.67,136.25,134.67,131.88,131.22$, $130.44,129.43,129.03,121.55,115.70,69.48,21.30$, 18.29. ESIHRMS: $\mathrm{m} / \mathrm{z}[\mathrm{M}+\mathrm{H}]^{+}$calcd for $\mathrm{C}_{22} \mathrm{H}_{23} \mathrm{BrNO}_{3} \mathrm{~S}^{+} 460.0582$, found 460.0587. HPLC, $t_{R}=9.530 \mathrm{~min}, 96.8 \%$ Purity, mobile phase: acetonitrile-water $(75: 25, v / v), \lambda=254 \mathrm{~nm}$.

\subsection{Biological Activity Tests 4.2.1 Reagents}

All chemical reagents and raw materials were purchased from the experimental consumables management platform of Shandong University (http://syhc.sdu.edu.cn), and the purity is greater than 95\%. High glucose DMEM medium was purchased from Hyclone, liposome 2000 was purchased from Invitrogen, fetal calf serum was purchased from Gibco, pancreatin was purchased from Gibco, plasmid GPR120-YFP and plasmid $\beta$-arrestin2-Rluc were purchased from Jinan Boshang Biotechnology Company, coelenterazine was purchased from Shanghai Jizhi Biochemical Co., Ltd, OPTI-MEM medium was purchased from Hyclone, Poloxamer F-127 and DMSO were purchased from Amresco, $\mathrm{Ca}^{2+}$ probe Fluo-4, am and HBSS (D-Hanks) were purchased from Biyuntian Biotechnology Co., Ltd.

Male 8-week-old C57BL/KsJ-db/db spontaneously diabetic mice were purchased from Beijing Weishanglide Biotechnology Co., Ltd.

\subsubsection{Optical Property}

The stocking solution of probes was diluted with acetonitrile to $40 \mu \mathrm{M}$, and their ultraviolet absorption spectrum was scanned with an ultraviolet spectrophotometer. Secondly, the excitation and emission spectra of probes at $10,20,30$, and $40 \mu \mathrm{M}$ with PBS buffer were measured with a microplate reader. Moreover, the excitation and emission spectrum were recorded in four solvents: $\mathrm{MeCN}, \mathrm{DMSO}, \mathrm{H}_{2} \mathrm{O}$, and EA, respectively.

\subsubsection{CCK8 Assay for Cytotoxicity}

The cytotoxicity of probes was measured in HEK293, PC-3, and $\mathrm{CHO}$ cells using the CCK8 method. Cells were firstly seeded into a transparent 96 -well plate $(100 \mu \mathrm{l}, 8000$ cells per well). After the cells were iron-walled, the compound solution was diluted with serum-free medium to different concentrations for the test. After a 24-h incubation, the medium was removed from the plate, and the CCK8 working solution was added. Finally, the absorbance at $450 \mathrm{~nm}$ was scanned after a 1-h incubation by the microplate reader.

\subsection{4 $\mathrm{Ca}^{2+}$ Flow Assay}

$\mathrm{Ca}^{2+}$ flow activity was determined in HEK293 cells stably transfecting the GPR120-Rluc gene. After incubating the cells for $24 \mathrm{~h}$, the medium was removed from the plate, and the cells were washed with HBSS buffer (without $\mathrm{Ca}^{2+}$ and $\mathrm{Mg}^{2+}$ ). Subsequently, a $2-\mu \mathrm{M}$ Fluo-4 AM working solution in HBSS buffer (without $\mathrm{Ca}^{2+}$ and $\mathrm{Mg}^{2+}$ ) was added to the plate ( $40 \mu \mathrm{l}$ per well). After incubating the cells for $20 \mathrm{~min}$ at $37^{\circ} \mathrm{C}$, compound solution at different concentrations in HBSS buffer (per well $160 \mu \mathrm{l}$ ) was added. Followed by a 40-min incubation, the solution was removed from the plate, HEPES buffer $(200 \mu$ l per well) was added, and the fluorescence intensity was detected using the microplate reader (Ex: $488 \mathrm{~nm}$; Em: $520 \mathrm{~nm}$ ) (Watterson et al., 2017).

$\mathrm{Ca}^{2+}$ flow activity was determined in $\mathrm{CHO}$ cells with transient GPR40 gene by the same method as well, in which the GPR40 agonist TAK875 was used as a positive control.

\subsubsection{Bioluminescence Resonance Energy Transfer Activity Test}

GPR120-YFP and $\beta$-arresting-2-Rluc plasmids were transfected into HEK293 cells. After a 24-h incubation, the cells were seeded in a black 96-well plate ( $100 \mu \mathrm{l}, 20,000$ cells per well). Followed by a 24 -h incubation, the solution was removed from the plate, and compounds with different concentrations $(100 \mu \mathrm{l}$ per well $)$ and coelenterazine $(10 \mu \mathrm{M}, 100 \mu \mathrm{l}$ per well) were added, followed by the fluorescence intensity was measured at 460 and $520 \mathrm{~nm}$ with the microplate reader (Christiansen et al., 2016; Hill et al., 2018).

\subsubsection{Fluorescence Imaging}

HEK293 and PC-3 cells were seeded in fluorescent confocal dishes $\left(5 \times 10^{3}\right.$ per well). After the cells were iron-walled, the medium was removed from the dishes, the cells were washed once with a serum-free medium, and the probe was added. After incubating the cells for $10 \mathrm{~min}$, the confocal dishes were observed by an inverted fluorescence microscope.

\subsubsection{Bioluminescence Resonance Energy Transfer Saturation Experiment}

HEK293 cells stably transfecting the GPR120-Rluc gene were seeded in two black 96 -well plates $\left(100 \mu \mathrm{l}, 2 \times 10^{4}\right.$ cells per well). After incubating the cells for $24 \mathrm{~h}$, the medium of the non-specific plate was removed, and positive control GSK134647A $(15 \mu \mathrm{M}$, $50 \mu \mathrm{l}$ per well) was added into each well. After a 40-min incubation, the medium was removed, and probe $\mathrm{N} 1$ was added into two plates $(100 \mu \mathrm{l}$ per well). Followed by incubation for $40 \mathrm{~min}$, coelenterazine was added to the plates (final concentration: $10 \mu \mathrm{M}, 100 \mu \mathrm{l}$ per well for specific plates; $50 \mu \mathrm{l}$ per well for non-specific plates). Finally, the fluorescence intensity was measured at 460 and $520 \mathrm{~nm}$ with the microplate reader after a 10-min incubation (Christiansen et al., 2016).

\subsubsection{Developing Bioluminescence Resonance Energy Transfer Competitive Experiment}

HEK293 cells stably transfected with the GPR120-Rluc gene were seeded in a black 96 -well plate $\left(100 \mu \mathrm{l}, 2 \times 10^{4}\right.$ cells per well). After the cells were incubated for $24 \mathrm{~h}$, the medium was removed, and probe N1 (400 nM, $50 \mu \mathrm{l}$ per well) was added. After a 30-min incubation, positive controls GSK134647A and TUG-891 (100 $\mu \mathrm{l}$ per well) were added. Followed by a 40-min incubation, coelenterazine was added to (final concentration: $10 \mu \mathrm{M}, 50 \mu \mathrm{l}$ per well) the plates. Thenceforward, the fluorescence intensity was measured at 450 and $550 \mathrm{~nm}$ with the microplate reader after a 10 -min incubation.

Using the same method, the BRET competition experiment was conducted at different concentrations of probe N1 (200 nM, $500 \mathrm{nM}, 1000 \mathrm{nM})$. 


\subsubsection{Bioluminescence Resonance Energy Transfer Kinetic Binding Experiment}

HEK293 cells stably transfecting the GPR120-Rluc gene were seeded in two entirely black 96 -well plates $\left(100 \mu \mathrm{l}, 2 \times 10^{4}\right.$ cells per well). After a 24 -h incubation, the medium was removed from the non-specific plate, coelenterazine was added to (final concentration: $10 \mu \mathrm{M}, 50 \mu \mathrm{l}$ per well) the plates, and BRET value was measured after a 5-min incubation. Probe N1 $(500 \mathrm{nM}, 100 \mu \mathrm{l}$ per well) was then added, and the BRET value was recorded in a 30-s interval for 6 minutes. Finally, GSK137647A was added (50 $\mu \mathrm{l}$ per well), and BRET value was measured in a 30 -s interval for $30 \mathrm{~min}$.

\subsubsection{The Activity Experiments of Agonists}

HEK293 cells stably transfected with the GPR120-Rluc gene were seeded in a black 96-well plate $\left(100 \mu \mathrm{l}, 2 \times 10^{4}\right.$ cells per well). After a 24 -h incubation, the medium was removed, probe $\mathrm{N} 1(400 \mathrm{nM}, 50 \mu \mathrm{l}$ per well) was added, and $10 \mu \mathrm{M}$ of the compound was added after a 30-min incubation as well. Followed by a 40-min incubation, coelenterazine (final concentration: $10 \mu \mathrm{M}, 50 \mu \mathrm{l}$ per well) was added to the plate. Afterward, the fluorescence intensity was measured at 450 and $550 \mathrm{~nm}$ with the microplate reader after another 10-min incubation.

\subsubsection{The Bias of Agonists}

The bias was quantified by Eq. 1, in which $\beta$ is the bias factor, $\mathrm{E}_{\max }$ is the maximum effect produced by the agonist, and $\mathrm{Pl}$ and P2 represents the $G_{q}$ and $\beta$-arrestin 2 signal pathway, respectively.

Formula 1:

$$
\beta=\log \left(\left(\frac{E_{\max , P 1}}{E C_{50, P 1}} \frac{E C_{50, P 2}}{E_{\max , P 2}}\right)_{\text {lig }} \times\left(\frac{E_{\max , P 2}}{E C_{50, P 2}} \frac{E C_{50, P 1}}{E_{\max , P 1}}\right)_{\text {ref }}\right)
$$

\subsubsection{The Blood Glucose Experiments}

All animal studies were approved by the Ethics Committee and IACUC of Cheeloo College of Medicine, Shandong University, and were conducted in compliance with European Guidelines for the Care and Use of Laboratory Animals. After adaptive feeding for $10-15$ days, the $\mathrm{db} / \mathrm{db}$ mice were divided into positive control group $(30 \mathrm{mg} / \mathrm{kg})$, low content compound group $(10 \mathrm{mg} / \mathrm{kg})$, high content compound group $(30 \mathrm{mg} / \mathrm{kg})$, and negative control group (the same volume dosing solvent). These mice were administrated by gavage once a day (administration volume, $20 \mathrm{ml} / \mathrm{kg}$ ) for four consecutive weeks. During the administration period, the fasting blood glucose (without food and water for $6 \mathrm{~h}$ ) was measured twice a week by using a blood glucose meter. The

\section{REFERENCES}

Alvarez-Curto, E., Inoue, A., Jenkins, L., Raihan, S. Z., Prihandoko, R., Tobin, A. B., et al. (2016). Targeted Elimination of G Proteins and Arrestins Defines Their Specific Contributions to Both Intensity and Duration of G Protein-Coupled Receptor Signaling. J. Biol. Chem. 291, 27147-27159. doi:10.1074/jbc.m116. 754887 blood glucose level was measured for four consecutive weeks. The data was processed with Graphpad 8.2 software (Cox et al., 2017; Zhang et al., 2017).

\subsubsection{Glucose Tolerance Test}

On the last day of the dosing cycle, the fasting blood glucose of mice was measured (without food and water for $6 \mathrm{~h}$ ), and glucose solution $(100 \mathrm{mg} / \mathrm{kg})$ was injected. The blood glucose was measured at six-time points $(5,10,30,60$, and $120 \mathrm{~min})$. Finally, the area under the curve was analyzed with SPSS 24 software.

\section{DATA AVAILABILITY STATEMENT}

The original contributions presented in the study are included in the article/Supplementary Material, further inquiries can be directed to the corresponding author.

\section{ETHICS STATEMENT}

The animal study was reviewed and approved by the Ethics Committee and IACUC of Cheeloo College of Medicine, Shandong University.

\section{AUTHOR CONTRIBUTIONS}

ML and LD conceived and designed the experiments. SM, ZL, YY, and $\mathrm{LZ}$ performed experiments. It is noteworthy that SM and ZL contributed equally to this work. ML and LD revised the manuscript. The final manuscript was approved by all authors.

\section{FUNDING}

The present work was supported by grants from the National Natural Science Foundation of China (No. 82173667) and the Key Research and Development Project of Shandong Province (No. 2018GSF118211).

\section{SUPPLEMENTARY MATERIAL}

The Supplementary Material for this article can be found online at: https://www.frontiersin.org/articles/10.3389/fchem.2022.816014/ full\#supplementary-material

Azevedo, C. M. G., Watterson, K. R., Wargent, E. T., Hansen, S. V. F., Hudson, B. D., Kępczyńska, M. A., et al. (2016). Non-Acidic Free Fatty Acid Receptor 4 Agonists with Antidiabetic Activity. J. Med. Chem. 59, 8868-8878. doi:10.1021/ acs.jmedchem.6b00685

Christiansen, E., Hudson, B. D., Hansen, A. H., Milligan, G., and Ulven, T. (2016). Development and Characterization of a Potent Free Fatty Acid Receptor 1 (FFA1) Fluorescent Tracer. J. Med. Chem. 59, 4849-4858. doi:10.1021/acs. jmedchem.6b00202 
Civelli, O., Reinscheid, R. K., Zhang, Y., Wang, Z., Fredriksson, R., and Schiöth, H. B. (2013). G Protein-Coupled Receptor Deorphanizations. Annu. Rev. Pharmacol. Toxicol. 53, 127-146. doi:10.1146/annurev-pharmtox-010611134548

Cox, J. M., Chu, H. D., Chelliah, M. V., Debenham, J. S., Eagen, K., Lan, P., et al. (2017). Design, Synthesis, and Evaluation of Novel and Selective G-Protein Coupled Receptor 120 (GPR120) Spirocyclic Agonists. ACS Med. Chem. Lett. 8, 49-54. doi:10.1021/acsmedchemlett.6b00360

Garrido, D. M., Corbett, D. F., Dwornik, K. A., Goetz, A. S., Littleton, T. R., McKeown, S. C., et al. (2006). Synthesis and Activity of Small Molecule GPR40 Agonists. Bioorg. Med. Chem. Lett. 16, 1840-1845. doi:10.1016/j.bmcl.2006. 01.007

Gurevich, V. V., and Gurevich, E. V. (2019). GPCR Signaling Regulation: The Role of GRKs and Arrestins. Front. Pharmacol. 10, 125. doi:10.3389/fphar.2019. 00125

Hansen, A. H., Sergeev, E., Pandey, S. K., Hudson, B. D., Christiansen, E., Milligan, G., et al. (2017). Development and Characterization of a Fluorescent Tracer for the Free Fatty Acid Receptor 2 (FFA2/GPR43). J. Med. Chem. 60, 5638-5645. doi:10.1021/acs.jmedchem.7b00338

Hansen, S. V. F., and Ulven, T. (2016). Pharmacological Tool Compounds for the Free Fatty Acid Receptor 4 (FFA4/GPR120). Handb Exp. Pharmacol. 236, 33-56. doi:10.1007/164_2016_60

Hauser, A. S., Attwood, M. M., Rask-Andersen, M., Schiöth, H. B., and Gloriam, D. E. (2017). Trends in GPCR Drug Discovery: New Agents, Targets and Indications. Nat. Rev. Drug Discov. 16, 829-842. doi:10.1038/nrd.2017.178

Hilgendorf, K. I., Johnson, C. T., Mezger, A., Rice, S. L., Norris, A. M., Demeter, J., et al. (2019). Omega-3 Fatty Acids Activate Ciliary FFAR4 to Control Adipogenesis. Cell 179, 1289-1305. doi:10.1016/j.cell.2019.11.005

Hill, R., Disney, A., Conibear, A., Sutcliffe, K., Dewey, W., Husbands, S., et al. (2018). The Novel $\mu$-opioid Receptor Agonist PZM21 Depresses Respiration and Induces Tolerance to Antinociception. Br. J. Pharmacol. 175, 2653-2661. doi:10.1111/bph.14224

Hirasawa, A., Tsumaya, K., Awaji, T., Katsuma, S., Adachi, T., Yamada, M., et al. (2005). Free Fatty Acids Regulate Gut Incretin Glucagon-like Peptide-1 Secretion through GPR120. Nat. Med. 11, 90-94. doi:10.1038/nm1168

Ichimura, A., Hirasawa, A., Poulain-Godefroy, O., Bonnefond, A., Hara, T., Yengo, L., et al. (2012). Dysfunction of Lipid Sensor GPR120 Leads to Obesity in Both Mouse and Human. Nature 483, 350-354. doi:10.1038/nature10798

Iliopoulos-Tsoutsouvas, C., Kulkarni, R. N., Makriyannis, A., and Nikas, S. P. (2018). Fluorescent Probes for G-Protein-Coupled Receptor Drug Discovery. Expert Opin. Drug Discov. 13, 933-947. doi:10.1080/17460441.2018.1518975

Jenkins, L., Brea, J., Smith, N. J., Hudson, B. D., Reilly, G., Bryant, N. J., et al. (2010). Identification of Novel Species-Selective Agonists of the G-Protein-Coupled Receptor GPR35 that Promote Recruitment of $\beta$-arrestin- 2 and Activate Ga13. Biochem. J. 432, 451-459. doi:10.1042/bj20101287

Klymchenko, A. S. (2017). Solvatochromic and Fluorogenic Dyes as EnvironmentSensitive Probes: Design and Biological Applications. Acc. Chem. Res. 50, 366-375. doi:10.1021/acs.accounts.6b00517

Leung, P. S., and Zhang, D. (2014). Potential Roles of GPR120 and its Agonists in the Management of Diabetes. Dddt 8, 1013-1027. doi:10.2147/dddt.s53892

Li, H., Huang, Q., Chen, C., Xu, B., Wang, H.-Y., and Long, Y.-Q. (2017). Discovery of Potent and Orally Bioavailable GPR40 Full Agonists Bearing Thiophen-2Ylpropanoic Acid Scaffold. J. Med. Chem. 60, 2697-2717. doi:10.1021/acs. jmedchem.6b01357

Liu, J., Tian, C., Jiang, T., Gao, Y., Zhou, Y., Li, M., et al. (2017). Discovery of the First Environment-Sensitive Fluorescent Probe for GPR120 (FFA4) Imaging. ACS Med. Chem. Lett. 8, 428-432. doi:10.1021/acsmedchemlett.7b00023

Liu, P., Ma, S., Yan, C., Qin, X., Zhao, P., Li, Q., et al. (2019). Discovery of SmallMolecule Sulfonamide Fluorescent Probes for GPR120. Anal. Chem. 91, 15235-15239. doi:10.1021/acs.analchem.9b04157

Ma, Z., Du, L., and Li, M. (2014). Toward Fluorescent Probes for G-ProteinCoupled Receptors (GPCRs). J. Med. Chem. 57, 8187-8203. doi:10.1021/ jm $401823 z$
Ma, Z., Lin, Y., Cheng, Y., Wu, W., Cai, R., Chen, S., et al. (2016). Discovery of the First Environment-Sensitive Near-Infrared (NIR) Fluorogenic Ligand for a1Adrenergic Receptors Imaging In Vivo. J. Med. Chem. 59, 2151-2162. doi:10. 1021/acs.jmedchem.5b01843

McCoull, W., Bailey, A., Barton, P., Birch, A. M., Brown, A. J. H., Butler, H. S., et al. (2017). Indazole-6-phenylcyclopropylcarboxylic Acids as Selective GPR120 Agonists with In Vivo Efficacy. J. Med. Chem. 60, 3187-3197. doi:10.1021/ acs.jmedchem.7b00210

Milligan, G., Shimpukade, B., Ulven, T., and Hudson, B. D. (2017). Complex Pharmacology of Free Fatty Acid Receptors. Chem. Rev. 117, 67-110. doi:10. 1021/acs.chemrev.6b00056

Miyamoto, J., Igarashi, M., Watanabe, K., Karaki, S.-i., Mukouyama, H., Kishino, S., et al. (2019). Gut Microbiota Confers Host Resistance to Obesity by Metabolizing Dietary Polyunsaturated Fatty Acids. Nat. Commun. 10, 4007. doi:10.1038/s41467-019-11978-0

Moniri, N. H. (2016). Free-fatty Acid Receptor-4 (GPR120): Cellular and Molecular Function and its Role in Metabolic Disorders. Biochem. Pharmacol. 110-111, 1-15. doi:10.1016/j.bcp.2016.01.021

Rajagopal, S., Ahn, S., Rominger, D. H., Gowen-MacDonald, W., Lam, C. M., Dewire, S. M., et al. (2011). Quantifying Ligand Bias at Seven-Transmembrane Receptors. Mol. Pharmacol. 80, 367-377. doi:10.1124/mol.111.072801

Shimpukade, B., Hudson, B. D., Hovgaard, C. K., Milligan, G., and Ulven, T. (2012). Discovery of a Potent and Selective GPR120 Agonist. J. Med. Chem. 55, 4511-4515. doi:10.1021/jm300215x

Sparks, S. M., Chen, G., Collins, J. L., Danger, D., Dock, S. T., Jayawickreme, C., et al. (2014). Identification of Diarylsulfonamides as Agonists of the Free Fatty Acid Receptor 4 (FFA4/GPR120). Bioorg. Med. Chem. Lett. 24, 3100-3103. doi:10.1016/j.bmcl.2014.05.012

Stoddart, L. A., Johnstone, E. K. M., Wheal, A. J., Goulding, J., Robers, M. B., Machleidt, T., et al. (2015). Application of BRET to Monitor Ligand Binding to GPCRs. Nat. Methods 12, 661-663. doi:10.1038/nmeth.3398

Sun, Q., Hirasawa, A., Hara, T., Kimura, I., Adachi, T., Awaji, T., et al. (2010). Structure-Activity Relationships of GPR120 Agonists Based on a Docking Simulation. Mol. Pharmacol. 78, 804-810. doi:10.1124/mol.110.066324

Watterson, K. R., Hansen, S. V. F., Hudson, B. D., Alvarez-Curto, E., Raihan, S. Z., Azevedo, C. M. G., et al. (2017). Probe-Dependent Negative Allosteric Modulators of the Long-Chain Free Fatty Acid Receptor FFA4. Mol. Pharmacol. 91, 630-641. doi:10.1124/mol.116.107821

Yan, Y., Jiang, W., Spinetti, T., Tardivel, A., Castillo, R., Bourquin, C., et al. (2013). Omega-3 Fatty Acids Prevent Inflammation and Metabolic Disorder through Inhibition of NLRP3 Inflammasome Activation. Immunity 38, 1154-1163. doi:10.1016/j.immuni.2013.05.015

Zhang, D., So, W. Y., Wang, Y., Wu, S. Y., Cheng, Q., and Leung, P. S. (2017). Insulinotropic Effects of GPR120 Agonists Are Altered in Obese Diabetic and Obese Non-diabetic States. Clin. Sci. 131, 247-260. doi:10.1042/cs20160545

Conflict of Interest: The authors declare that the research was conducted in the absence of any commercial or financial relationships that could be construed as a potential conflict of interest.

Publisher's Note: All claims expressed in this article are solely those of the authors and do not necessarily represent those of their affiliated organizations, or those of the publisher, the editors and the reviewers. Any product that may be evaluated in this article, or claim that may be made by its manufacturer, is not guaranteed or endorsed by the publisher.

Copyright $\odot 2022 \mathrm{Ma}$, Li, Yang, Zhang, Li and Du. This is an open-access article distributed under the terms of the Creative Commons Attribution License (CC BY). The use, distribution or reproduction in other forums is permitted, provided the original author(s) and the copyright owner(s) are credited and that the original publication in this journal is cited, in accordance with accepted academic practice. No use, distribution or reproduction is permitted which does not comply with these terms. 